\title{
Naturally occurring taiwaniaquinoids: biosynthetic relationships and synthetic approaches
}

\author{
Vishnumaya Bisai, ${ }^{* a}$ Aditi Gupta, ${ }^{\text {and Alakesh Bisai*c }}$
}

${ }^{a}$ Department of Chemistry, Indian Institute of Science Education and Research Berhampur, Government ITI, Engineering School Junction, Berhampur, Odisha 760 010, India; ${ }^{b}$ Department of Chemistry, St. Stephen's College, Delhi University, India; 'Department of Chemistry, Indian Institute of Science Education and Research Bhopal, Bhauri, Bhopal - 462066, Madhya Pradesh, India

Email: vishnumayabisai@gmail.com; alakesh@iiserb.ac.in

Received 05-20-2018

Accepted 07-11-2018

Published on line 09-01-2018

\section{Abstract}

The diterpenoids possessing a fused 6,5,6-abeo-abietane skeleton (1, Figure 1) have gained interest from synthetic community owing to their significant biological properties in addition to interesting complex architecture. These are a family of carbotricyclic diterpenoids bearing an unusual 4a-methyltetra- (and hexa-) hydrofluorene skeleton with an all-carbon quaternary stereocenter. A number of abeo-abietanes isolated from different East Asian conifers viz. Taiwanese pine tree Taiwania cryptomerioides and hence they are popularly named as the taiwaniaquinoids. In this review article, we discuss on the biosynthetic proposal as well as recent efforts on the total syntheses of naturally occurring complex taiwaniaquinoids.

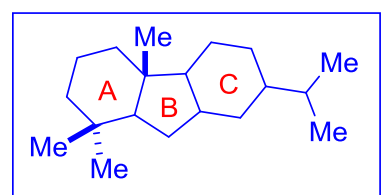

abeo-abietane skeleton (1)

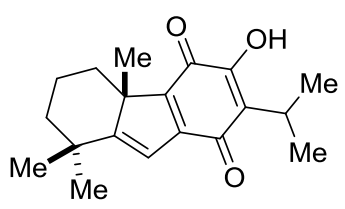

dichroanone (1a)

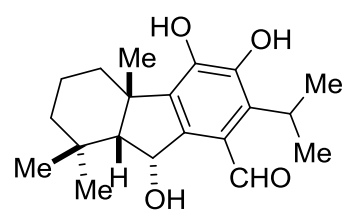

dichroanal A (1b)

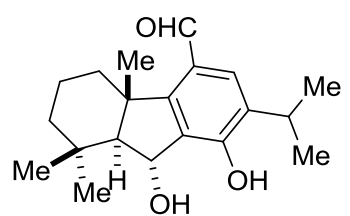

standishinal (1c)

Keywords: Taiwaniaquinoids, abeo-abietane diterpenoids, natural products, total synthesis, biological activities 


\section{Table of Contents}

1. Introduction

2. Biological Profiles of Taiwaniaquinoids (abeo-Abietane Diterpenoids)

3. Proposed Biosynthesis of Taiwaniaquinoids

4. Representatives of Taiwaniaquinoids

5. Synthetic Approaches to the Taiwaniaquinoids

5.1 Total syntheses of ( \pm )-taiwaniaquinoids

5.2 Stereocontrolled total syntheses of taiwaniaquinoids

6. Conclusions

Acknowledgements

References and notes

Authors biographies

\section{Introduction}

Naturally occurring terpenoids and their derivatives have greatly impacted the human experience. Nearly every human on earth has experienced their effects as flavors, fragrances, poisons, and medicines. In this context, taiwaniaquinoid based natural products are a subset of abeo-abietane, ${ }^{1}$ which constitute an important class of diterpenoids (Figure 1). The taiwaniaquinoids share 6,5,6-carbotricyclic core [abeo-abietane diterpenoids 1] and are biosyntically proposed to be arisen from a 6,6,6-abietane skeleton ${ }^{2}(\mathbf{2}$, Figure 1$)$ via degradation of one carbon unit from ' $\mathrm{B}$ '-ring.

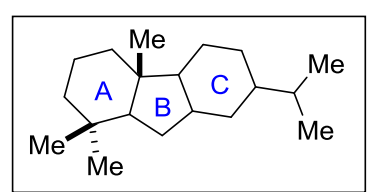

abeo-abietane skeleton (1) or taiwanaquinoid (1)

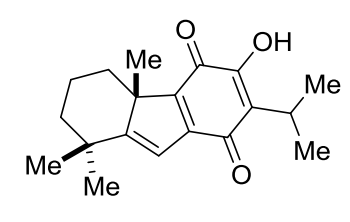

dichroanone (1a)

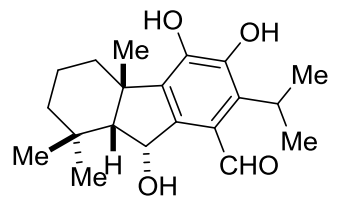

dichroanal A (1b)

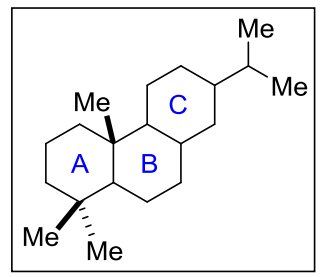

abietane skeleton (2)

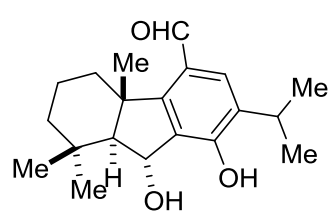

standishinal (1c)

Figure 1. Representative skeleton of abeo-abietane and abietane diterpenoids.

Diterpenoids possessing a fused 6,5,6-abeo-abietane skeleton (1, Figure 1) have gained substantial interest owing to their significant biological properties and interesting architecture. ${ }^{3}$ These are a family of carbotricyclic diterpenoids bearing an unusual 4a-methyltetra- (and hexa-) hydrofluorene structures. Taiwania cryptomerioides Hayata (Taxodiaceae) is an economically important, decay-resistant evergreen tree indigenous to the central mountains of Taiwan. Since 1995, a number of abeo-abietanes isolated from different East Asian conifers viz. Taiwanese pine tree Taiwania cryptomerioides and hence they are named as 


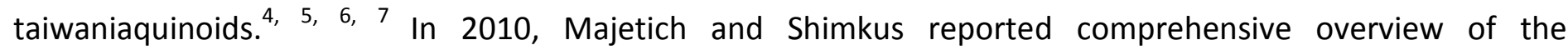
taiwaniaquinoid family of natural products summarizing the isolation, biosynthesis, and biological activities followed by a discussion of various synthetic strategies to the skeletal framework during 1995-2010. ${ }^{3}$ Very recently, in 2016, Shi and Guo have reported an excellent review on fluorenone and fluorenone containing natural products highlighting case studies of syntheses representing members of different subgroups. ${ }^{8}$

\section{Biological Profiles of Taiwaniaquinoids (abeo-Abietane Diterpenoids)}

Total synthesis of natural products is important area of research, as many of the current available drugs are natural products or their derivatives. The advantage of drugs derived from natural products with respect to fully synthesized compounds is their greater structural complexity. Also, the derivatives of natural product tend to be more selective toward a wide range of targets. As per literature report, few members of taiwaniaquinoids are found to exhibit potent cytotoxic activity against KB epidermoid carcinoma cancer cells ${ }^{9}$ and one of the members standishinal (1c), could be a promising candidate in breast cancer therapy, due to its aromatase inhibitory potential. ${ }^{10,11,12}$ These biological activities together with their intriguing carbotricyclic structure make taiwaniaquinoids an attractive synthetic target leading to elegant approaches to this class of diterpenoids.

The promising biological activity and the unusual structure of these terpenoids have stimulated research into the synthesis of this type of compound, ${ }^{13,14,15}$ including total and stereoselective syntheses. The synthesis starting with natural terpenoids facilitates the formation of enantiopure taiwaniaquinoids. Recently, Chahboun and Alvarez-Manzaneda and co-workers ${ }^{16}$ have synthesized new taiwaniaquinoids starting from natural terpenoids and the evaluation of their in vitro antiproliferative activities, as well as that of other synthesized taiwaniaquinoids, against human breast, colon, and lung tumor cells. This group has shown that, the in vitro antiproliferative activities of some taiwaniaquinoids and related compounds with functionalized $A$, $B$, or $C$ rings against human breast (MCF-7), colon (T-84), and lung (A-549) tumor cell lines were assayed (Figure 2). ${ }^{16}$ It is discovered that the most potent compounds 3a-c were more effective than the naturally occurring taiwaniaquinones $A(\mathbf{1 d})$ and $F(\mathbf{1 e})$ in all above three cell lines. The structure-activity relationship study of these new taiwaniaquinoids highlighted the correlation between the bromo substituent and the antiproliferative activity, especially in MCF-7 (human breast) cells. These findings indicate that some of the taiwaniaquinoids might be useful as cytostatic agents against breast, colon, and lung cancer cell lines. Therefore, further studies are welcome towards this direction.

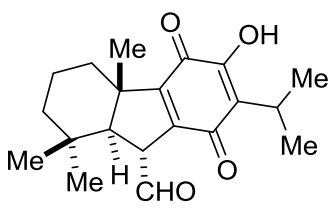

taiwaniaquinone $\mathrm{A}(\mathbf{1 d})$

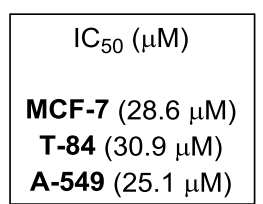

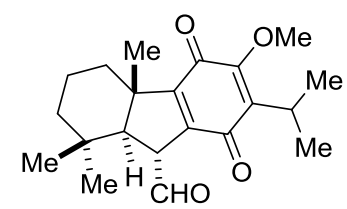

taiwaniaquinone $\mathrm{F}(\mathbf{1 e})$

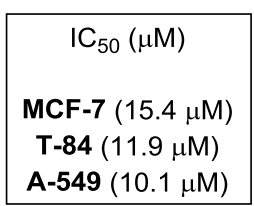

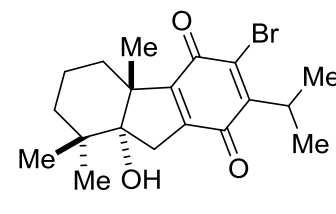

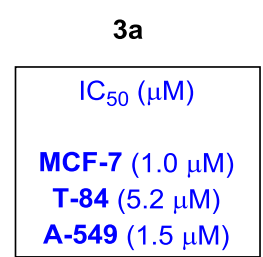

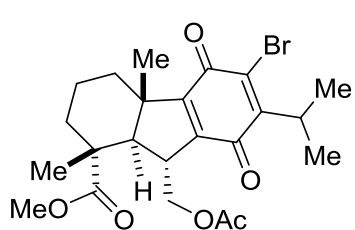

$3 b$

$\mathrm{IC}_{50}(\mu \mathrm{M})$

MCF-7 $(2.4 \mu \mathrm{M})$

T-84 $(2.9 \mu \mathrm{M})$

A-549 $(2.4 \mu \mathrm{M})$

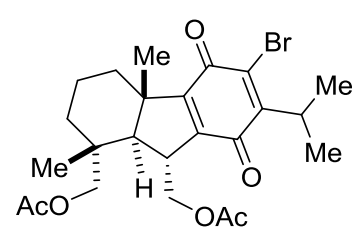

$3 c$

$\mathrm{IC}_{50}(\mu \mathrm{M})$

MCF-7 $(1.8 \mu \mathrm{M})$

T-84 (1.6 $\mu \mathrm{M})$

A-549 (1.1 $\mu \mathrm{M})$

synthetic analogues of taiwaniaquinoids are more active than taiwaniaquinones $A(\mathbf{1 d})$ and $F(1 \mathbf{e})$

Figure 2. abeo-Abietane diterpenoids, taiwaniaquinones A (1d), F (1e) and analogues 3a-c. 


\section{Proposed Biosynthesis of Taiwaniaquinoids (abeo-Abietane Diterpenoids)}

A plausible biogenetic pathway of taiwaniaquinoids (abeo-abietane diterpenoids) from abietane diterpenoids is shown in Scheme $1 .^{3}$ As per Node et. al., ${ }^{17}$ biosynthetically, the abeo-abietane diterpenoid skeleton is believed to be arisen from a Prins-type alkylations of dialdehyde 5 (alkylation at ortho-position of phenol), ${ }^{17}$ which in turn can be synthesized biogenetically from a more common abietane skeleton ferruginoldiol (4b) via

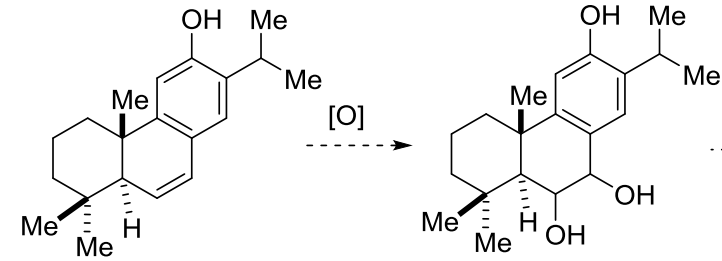

dehydroferruginol (4a) ferruginoldiol (4b)

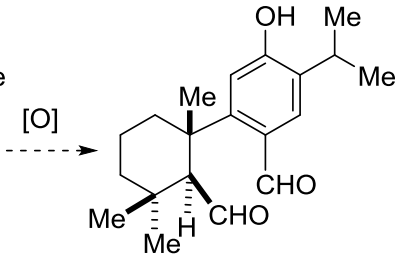

$5 a$

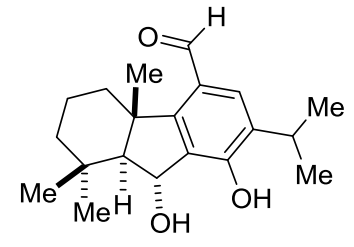

standishinal (1c)

Biogenetic Pathway following a key Prins type Reaction<smiles>CC(C)c1cc2c(cc1O)C(O)C(O)C1(C)CCCC[C@@]21C</smiles>

ferruginoldiol (4b)

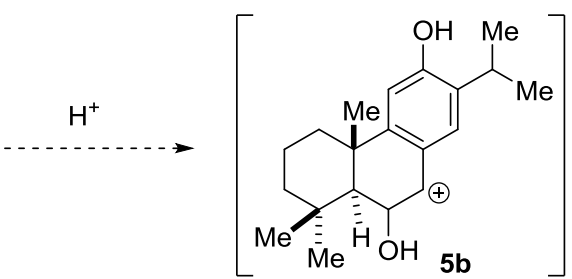

Biogenetic Pathway following a key Pinacol Rearrangement

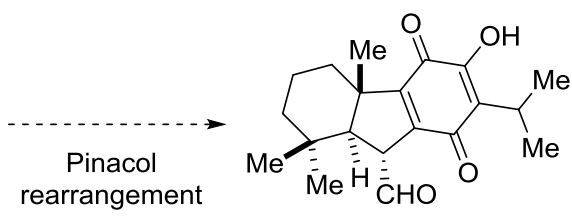

taiwaniaquinone $\mathrm{F}(\mathbf{1 t})$

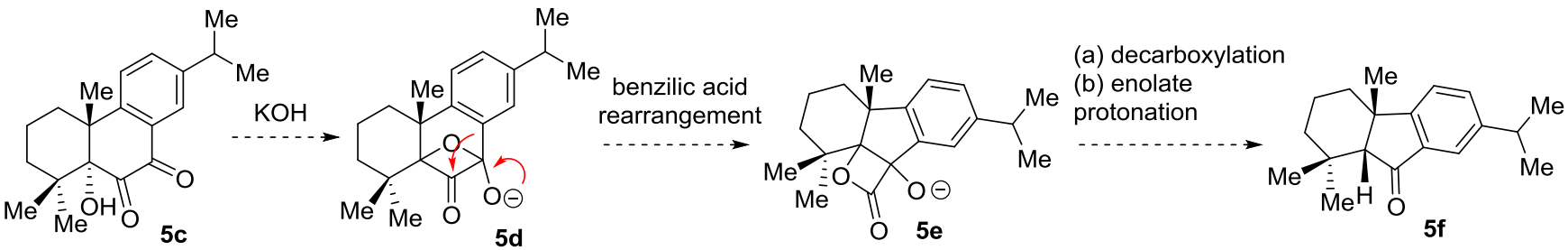

Biogenetic Pathway following a key Benzilic Acid Rearrangement

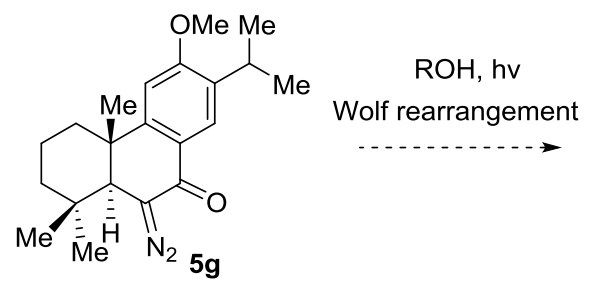

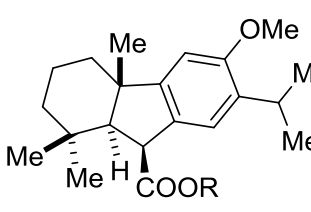

$5 \mathrm{~h}$

Biogenetic Pathway following a key Wolf Rearrangement
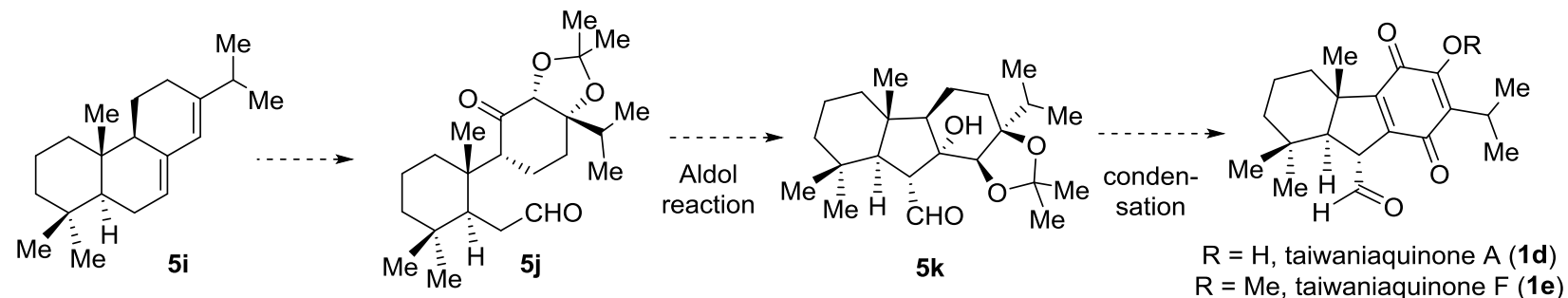

Biogenetic Pathway following a key Aldol Condensation

Scheme 1. Biosynthetic relationship of abeo-abietane and abietane diterpenoids. 
an oxidative cleavage of vicinal diol (Scheme 1). Hypothetical precursor ferruginoldiol (4b) can be obtained from an oxidation event of dehydroferruginol (4a) or from other congeners of abietane diterpenoids (Scheme 1). A biogenetic proposal for the synthesis of taiwaniaquinoids is reported to go through a key Pinacol rearrangement (Scheme 1 ) of $\mathbf{5 b}$ generated from ferruginoldiol $(\mathbf{4 b}) .^{18}$

In 2010, Gademann's biogenetic proposal for the synthesis of taiwaniaquinoid skeleton $\mathbf{5} f$ relies on a key benzilic acid rearrangement of $\mathbf{5} \mathbf{c}$ through the intermediates $\mathbf{5} \mathbf{d}$ and $\mathbf{5 e}$ (Scheme 1$).{ }^{19}$ Later, the same group, in 2013, had reported a biogenetic proposal for the synthesis of taiwaniaquinol A (10) via Wolf rearrangement of $\mathbf{5 g}$ through the intermediacy of ester $\mathbf{5 h}$ (Scheme 1). ${ }^{20}$ In 2010, Alvarez-Manzaneda and coworkers have shown a proposal for the synthesis of taiwaniaquinone $A(\mathbf{1 d})$ and taiwaniaquinone $F(\mathbf{1 E})$ via a key Aldol condensation aldehyde $\mathbf{5} \mathbf{j}$ (which was synthesized from $\mathbf{5 i}$ ) through the intermediacy of carbotricyclic core $\mathbf{5 k}$ (Scheme 1$){ }^{21}$

\section{Representatives of Taiwaniaquinoids (abeo-Abietane Diterpenoids)}

Since 1995, a number of abeo-abietane diterpenoids have been isolated from various sources. The representatives of these diterpenoids are shown in Figures 4-6. In 1995, while continuing their investigation of the leaf extracts, Cheng et al. discovered ${ }^{22,23}$ a new family of diterpenoids (four diterpenes and one norditerpene) possessing a [6,5,6]-abeo-abietane skeleton ${ }^{24}$ previously unknown in nature. ${ }^{25}$ They named these compounds as taiwaniaquinones $A(\mathbf{1 d}), B(\mathbf{1 n})$, and C (1) and taiwaniaquinols $A(\mathbf{1 0})$ and $B$ (1f) (Figures 3 and 4 ) according to their botanical origin, C-ring functionality, and order of isolation, respectively.
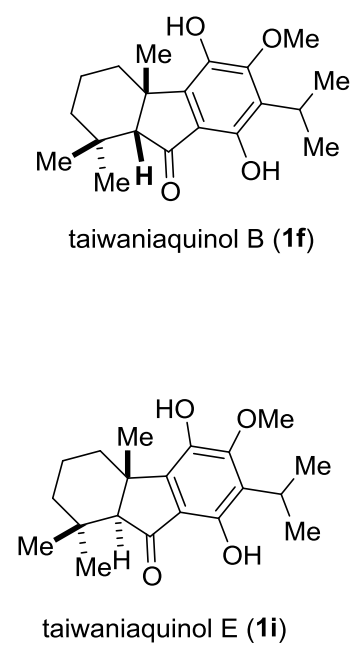
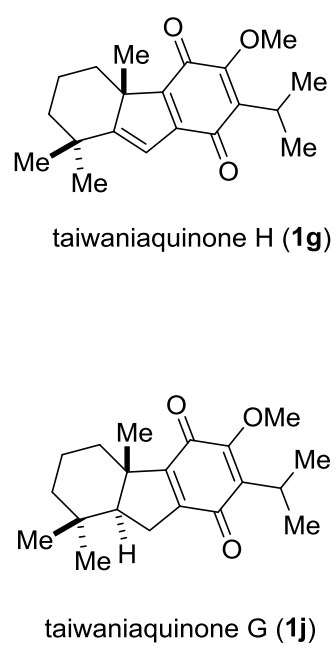
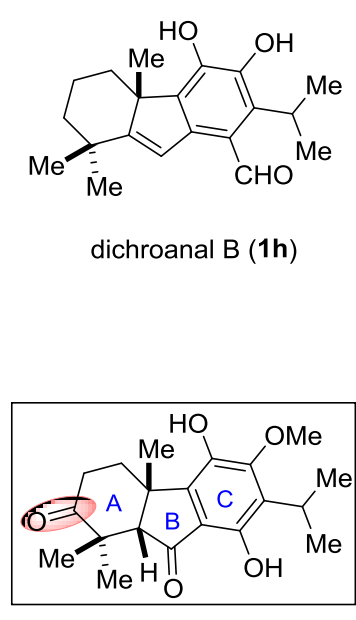

taiwaniaquinol $\mathrm{F}(\mathbf{1 k})$

Figure 3. abeo-Abietane diterpenoids sharing all-carbon quaternary stereocenters.

Cheng's continued work expanded this family in 1996, when the leaf extracts yielded taiwaniaquinones D (1s) and E (1q) (Figure 7). ${ }^{23}$ A similar skeleton was soon discovered in other families of abietane-rich plants. In 1999, Kawazoe et al. reported the isolation of three structurally similar compounds (Figures 1 and 3) from the roots of Salvia dichroantha Stapf (Lamiaceae), a Turkish flowering sage. These new compounds were named dichroanals $A(\mathbf{1 b})$ and $B(\mathbf{1 h})$ and dichroanone (1a). ${ }^{26}$ 


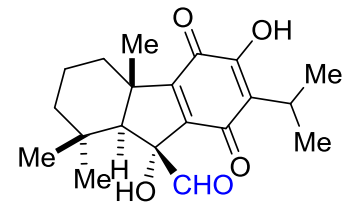

taiwaniaquinone $C(11)$

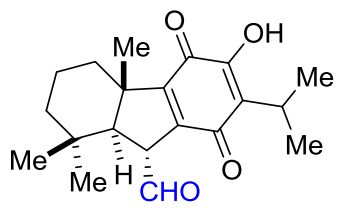

caryopincaolide $\mathrm{H}(\mathbf{1 p})$

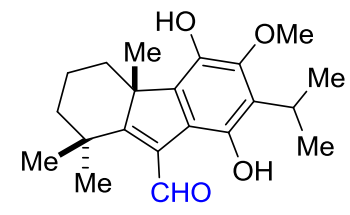

taiwaniaquinol D (1m)

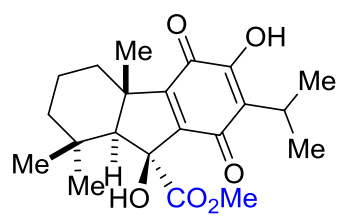

taiwaniaquinone $\mathrm{E}$ (1q)

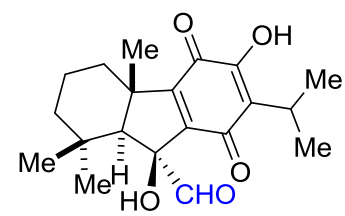

taiwaniaquinone $B(\mathbf{1 n})$

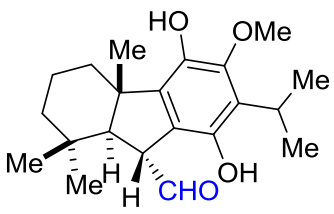

taiwaniaquinol C (1r)

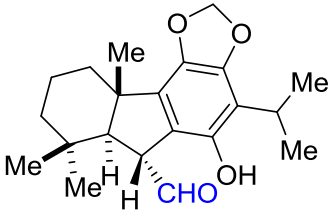

taiwaniaquinol $\mathrm{A}(\mathbf{1 0})$

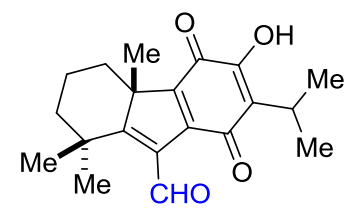

taiwaniaquinone $\mathrm{D}(\mathbf{1 s})$

Figure 4. abeo-Abietane diterpenoids sharing an additional carbon.

Tanaka and co-workers have isolated the compound designated standishinal (1c) from the bark of Thuja standishii (Cupressaceae), a Japanese conifer, in the same year. ${ }^{27}$ Meanwhile, Kuo et al. reinvestigated the bark extracts from $T$. cryptomerioides, and the structures of taiwaniaquinone $F(\mathbf{1 k})$ and taiwaniaquinols $C(\mathbf{1} \mathbf{r})$ and $D(\mathbf{1 m})$ were reported in $2003 .{ }^{28}$ Further study of the bark extract resulted in the 2005 report of taiwaniaquinones $\mathrm{G}(\mathbf{1} \mathbf{j})$ and $\mathrm{H}(\mathbf{1} \mathbf{g})$ and taiwaniaquinols $\mathrm{E}(\mathbf{1} \mathbf{i})$ and $\mathrm{F}(\mathbf{1} \mathbf{k}){ }^{29}$ Figure 7 shows a number of abeoabietane diterpenoids having an additional carbon as compared to taiwaniaquinoids shown in figure $6 .{ }^{30}$ It is also interestingly to note that there could be oxidized A-ring present in taiwanaquinoids, such as taiwaniaquinol F (1k) (Figure 6).

\section{Synthetic Approaches to the Taiwaniaquinoids (abeo-Abietane Diterpenoids)}

The synthetic approaches to this class of diterpenoids are shown in sections 5.1 and 5.2 .

\subsection{Total syntheses of ( \pm )-taiwaniaquinoids}

In 2003, Banerjee et. al. ${ }^{31,32}$ reported first general and convergent route for the synthesis of taiwaniaquinoids by utilizing a common cis-fused hexahydrofluorenone intermediate $\mathbf{6 d}$ (Scheme 2). Compound 6d was obtained via $\mathrm{Pd}(0)$-catalyzed reductive cyclization of $6 c^{31}$ which in turn was synthesized from Hagemann's ester (6a) and benzyl bromide (6b) in 5 steps. Carbotricylcic core $\mathbf{6 d}$ was elaborated to intermediate $\mathbf{6 e}$ in seven overall steps. Utilizing above strategy, the first total syntheses of ( \pm )-dichroanone (1a) and ( \pm )-dichronal $B(\mathbf{1 h})$ has been realized through a simple and convergent route (Scheme 2$).{ }^{31}$ In this strategy, required benzyl bromide (6b) was obtained from commercially available vanillin using a sequence of standard reactions, with $27 \%$ yield over seven steps. Later, same strategy has been successfully utilized for total syntheses of $( \pm)$ taiwaniaquinones $\mathrm{D}(\mathbf{1 s})$ and $\mathrm{H}(\mathbf{1 g})$, ( \pm )-taiwaniaquinol B (1f) by the Banerjee group (Scheme 2). ${ }^{32}$ 
<smiles>[X]C1=CC(=O)CCC1C(C)=O</smiles>

$6 a$<smiles>COc1c(Br)ccc(CBr)c1Br</smiles>

6b

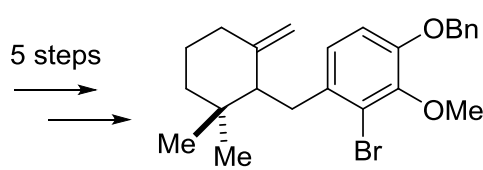

$6 c$

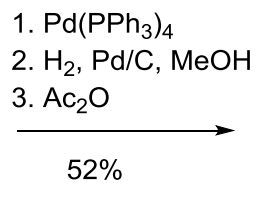

7 steps

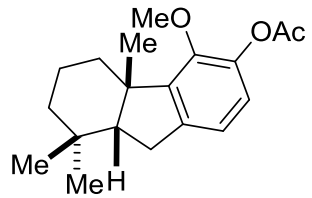

6d

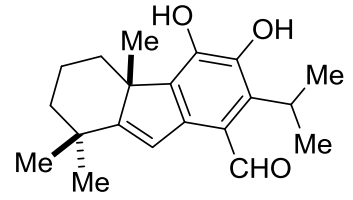

( \pm )-dichroanal B (1h)

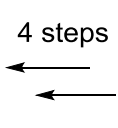

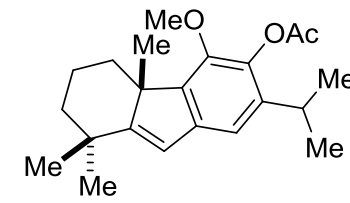

$6 e$

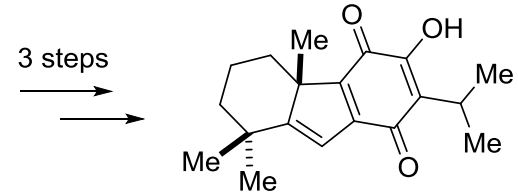

( \pm )-dichroanone (1a)

Scheme 2. Intramolecular Heck strategy by Banerjee (2003).

In 2005, Fillon and Fishlock reported the first total synthesis of taiwaniaquinol B (1a) in 15 steps and 6\% overall yield (Scheme 3). The key feature of this approach is a TMSOTf-mediated intramolecular Friedel-Crafts acylation/carbonyl $\alpha$-tert-alkylation domino reaction ${ }^{33}$ of compound $\mathbf{7 d}$ to furnish carbotricyclic ketone $\mathbf{7 e}$ (70\% yield). Intermediate 7e was further elaborated towards total synthesis of taiwaniaquinol B (1f) over 3 steps. Compound 7d was synthesized from 7c via a 1,4-addition, which in turn was synthesized from arylketone $\mathbf{7 b}$ in $61 \%$ yield by reacting with Meldrum's ester (Scheme 3 ). The arylketone $\mathbf{7 b}$ was synthesized from a commercially available 3,5-dihydroxybenzoic acid in 34\% overall yields over 7 steps.

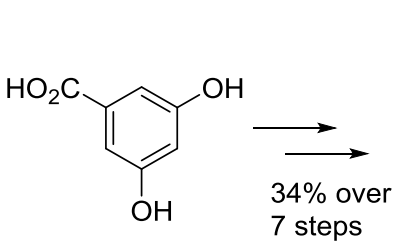

$7 a$

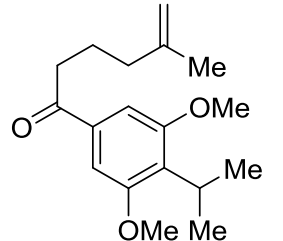

$7 \mathbf{b}$
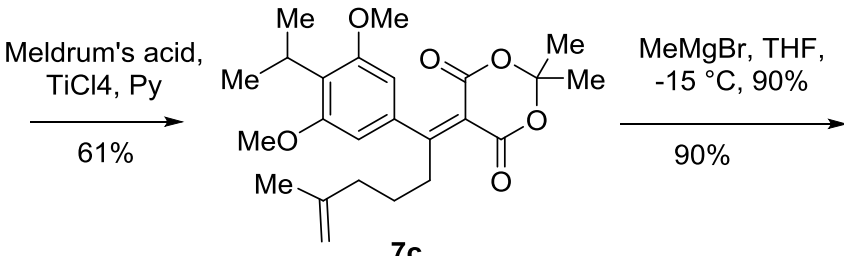

7c

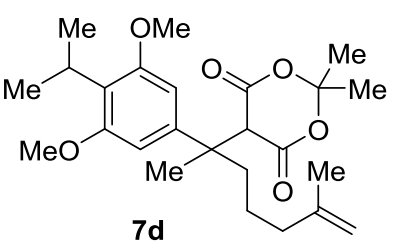

$7 d$

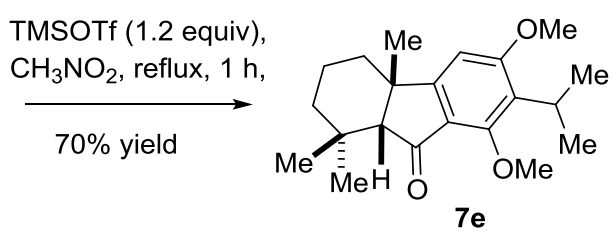

$7 e$

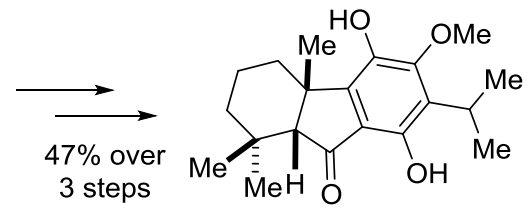

( \pm )-taiwaniaquinol B (1f)

Scheme 3. Intramolecular domino Friedel-Crafts acylation/carbonyl $\alpha$-tert-alkylation by Fillon (2005).

Node and co-worker, in 2006, have developed a new efficient method to prepare a $4 a$ methyltetrahydrofluorene system. The key reaction of this approach is an intramolecular Heck cyclization of the novel diene compound with a triflate functionality $\mathbf{8 c}$ to furnish carbotricyclic core $\mathbf{8 d}($ Scheme 4$) .^{34}$ The methodology was applied to the synthesis of $( \pm)$-dichroanal B $(\mathbf{1} \mathbf{h})$ with an improved yield, compared to the previously reported total synthesis. The required arene triflate $\mathbf{8 c}$ was synthesized from arylvinylcarbinol $\mathbf{8 b}$ in 4 steps, which in turn was synthesized from acetophenone $\mathbf{8 a}$ in 5 steps (Scheme 4). This methodology also provides the opportunity for a convenient construction of chiral 4a-methyltetrahydrofluorene. 

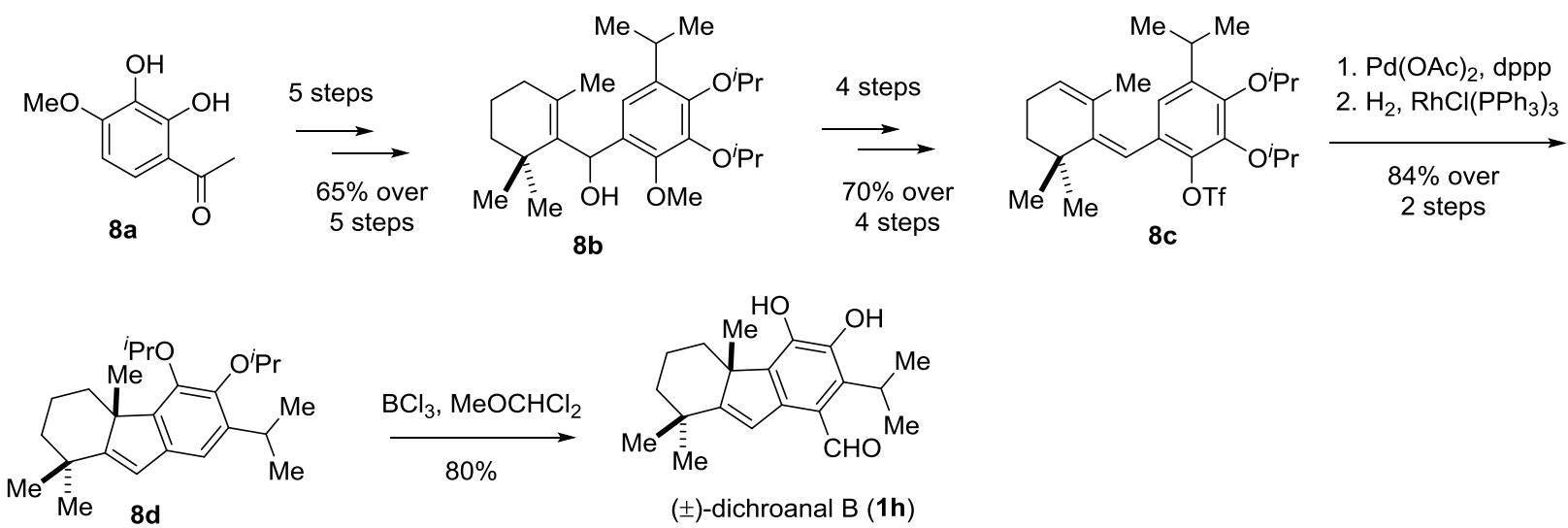

Scheme 4. Intramolecular Heck strategy by Node (2006).

In 2006, Trauner et. al. reported total synthesis of ( \pm )-taiwaniaquinol B (1f), ( \pm )-taiwaniaquinone $\mathrm{H}(\mathbf{1 g})$ and ( \pm )-dichroanone (1a) via a key Nazarov cyclization. ${ }^{35}$ Lithiation of bromoarene 9a followed by reaction with commercially available $\beta$-cyclocitral 10 afforded aryl vinyl carbinol $\mathbf{9 b}$, which was oxidized immediately to yield aryl vinyl ketone 9c (Scheme 5). It is reported that 9c could be cyclized in the presence of trimethylsilyl triflate (TMSOTf) in nitromethane to afford the highly unstable silyl enol ether 9e, presumably through the intermediacy of cation 9d. Upon aqueous workup, this procedure afforded the thermodynamically more favorable cis-indane product $\mathbf{9 f}$ as the only stereoisomer observed, from where ( \pm )-taiwaniaquinol B (1f) was synthesized in 3 steps, viz. selective demethylation by $\mathrm{BCl}_{3}$, oxidation in the presence of CAN [ceric(IV) ammonium nitrate], and reduction of $p$-bezoquinone with $\mathrm{Na}_{2} \mathrm{~S}_{2} \mathrm{O}_{4}$ to quinol.
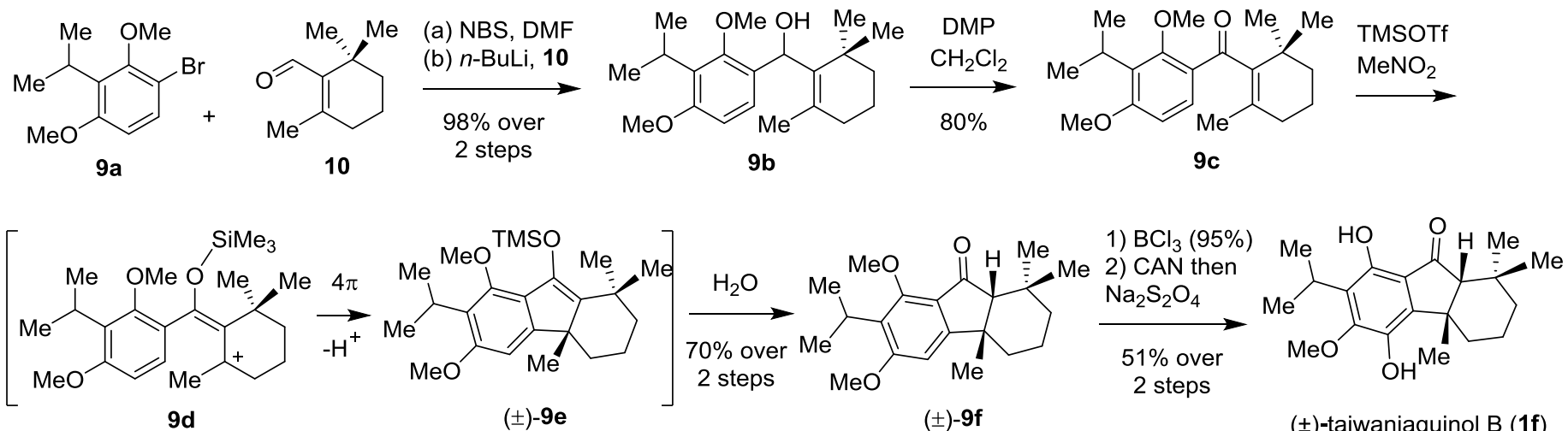

Scheme 5. Collective total syntheses of taiwaniaquinoids by Taruner.

Interestingly, heating of aryl vinyl ketone 9c with triflic anhydride in the presence of a hindered base (2,6di-tert-butylpyridine; 2,6-DTBP) cleanly afforded trifloxy indene $\mathbf{1 1 b}$ through the intermediacy of cation $\mathbf{1 1 a}$ (Scheme 6). This reaction is proposed to proceed through $4 \pi$ electrocyclization of intermediate cation 11a followed by deprotonation to yield $\mathbf{1 1} \mathbf{b}$. Later, $\mathrm{Pd}(0)$-catalyzed reduction of $\mathbf{1 1} \mathbf{b}$ gave indene $\mathbf{1 1}$ c in excellent yield. Complete demethylation followed by oxidation catalyzed by salcomine (11d) gave ( \pm )-dichroanone (1a). Alternatively, following a more selective demethylation and oxidation they completed total synthesis of $( \pm)$ taiwaniaquinol $\mathrm{H}(\mathbf{1 g})^{35}$ 

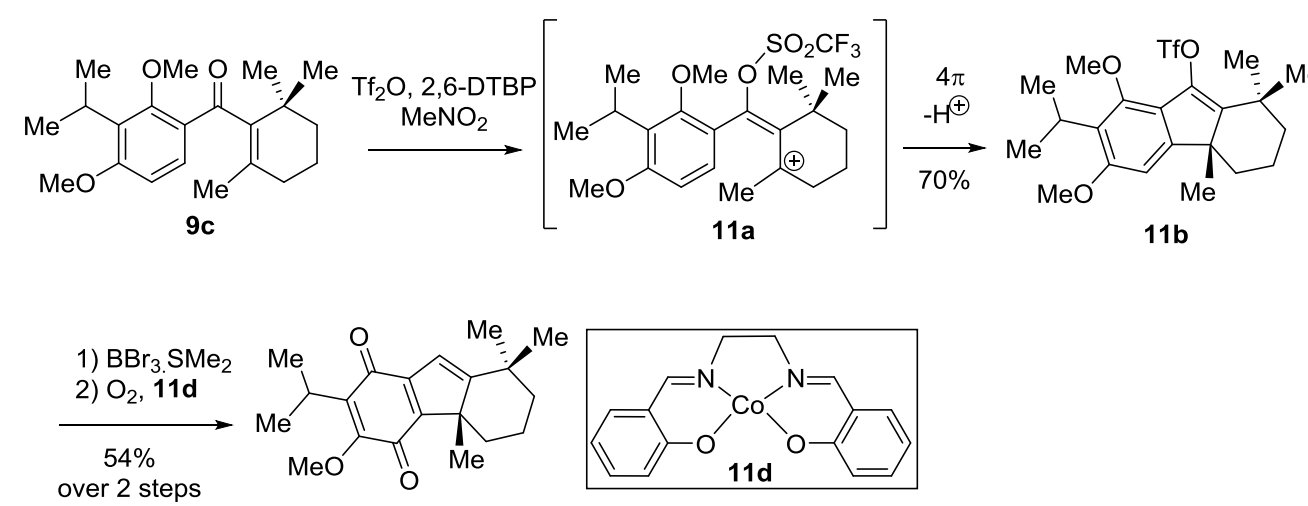

( \pm )-taiwaniquinone $\mathrm{H}(\mathbf{1 g})$

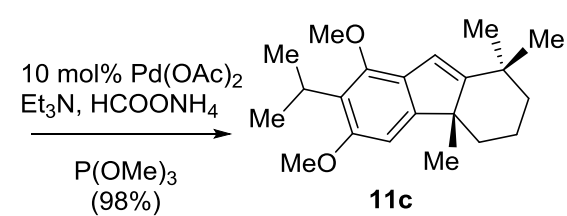

1) $\mathrm{BBr}_{3} \mathrm{SMe}_{2} \mid 45 \%$

2) $\mathrm{O}_{2}, \mathbf{1 1 d}$ over 2 steps

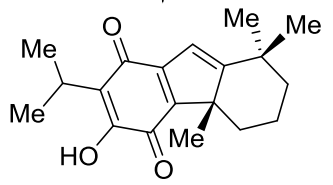

( \pm )-dichroanone (1a)

Scheme 6. Collective total syntheses of taiwaniaquinoids by Taruner (2006).

In 2008, Chiu and co-worker, ${ }^{36}$ have reported an efficient route for the synthesis of the hydrofluorenone skeleton by sequential cationic cyclizations promoted by acid (Scheme 7). From enone 12b (prepared from bromoarene 12a and geranyl aldehyde over 2 steps), the cyclization using $\mathrm{SnCl}_{4}$ afforded arylketone $12 \mathrm{c}$ in $89 \%$ yield. Later, cyclization of 12c was induced by Brønsted acid to afford carbotricyclic core $12 \mathrm{~d}$ in 2 steps in $54 \%$ overall yield (Scheme 7). This route is applicable to the synthesis of other taiwaniaquinoid natural products and analogues with similar skeletons, e.g. total synthesis of ( \pm )-taiwaniaquinol B (1f) was achieved from $12 \mathrm{~d}$ over 2 steps viz. selective demethylation, oxidation, and reduction protocol.
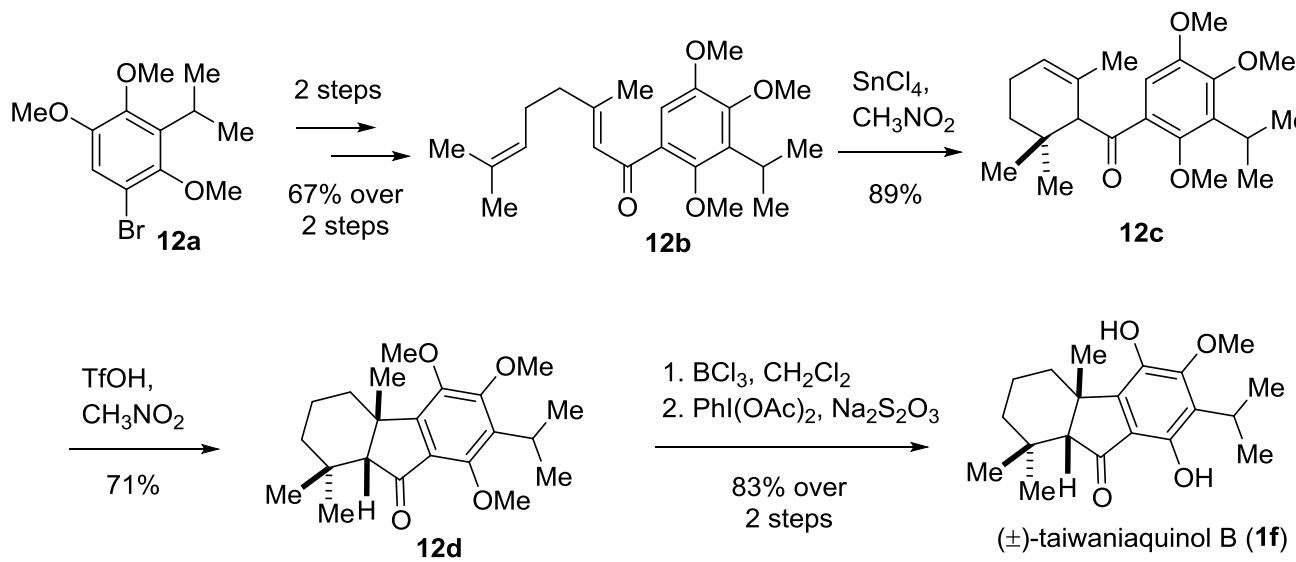

Scheme 7. Total synthesis of ( \pm )-Taiwaniaquinol B (1f) by Chiu (2008).

She and co-workers, ${ }^{37}$ in 2008, have reported efficient synthesis of carbotricyclic core 13 c related to the taiwaniaquinoids starting from aldehyde 13a and arene 13b in the presence of Eaton's reagent (Scheme 8). The process essentially follows a domino Friedel-Craft Acylation/Alkylation reactions to yield 13c in 64-70\% overall yield. Total syntheses of $( \pm)$-taiwaniaquinol B (1f) and ( \pm )-dichroanone (1a) were accomplished from intermediate $13 \mathrm{c}$ as shown in Scheme 8. 


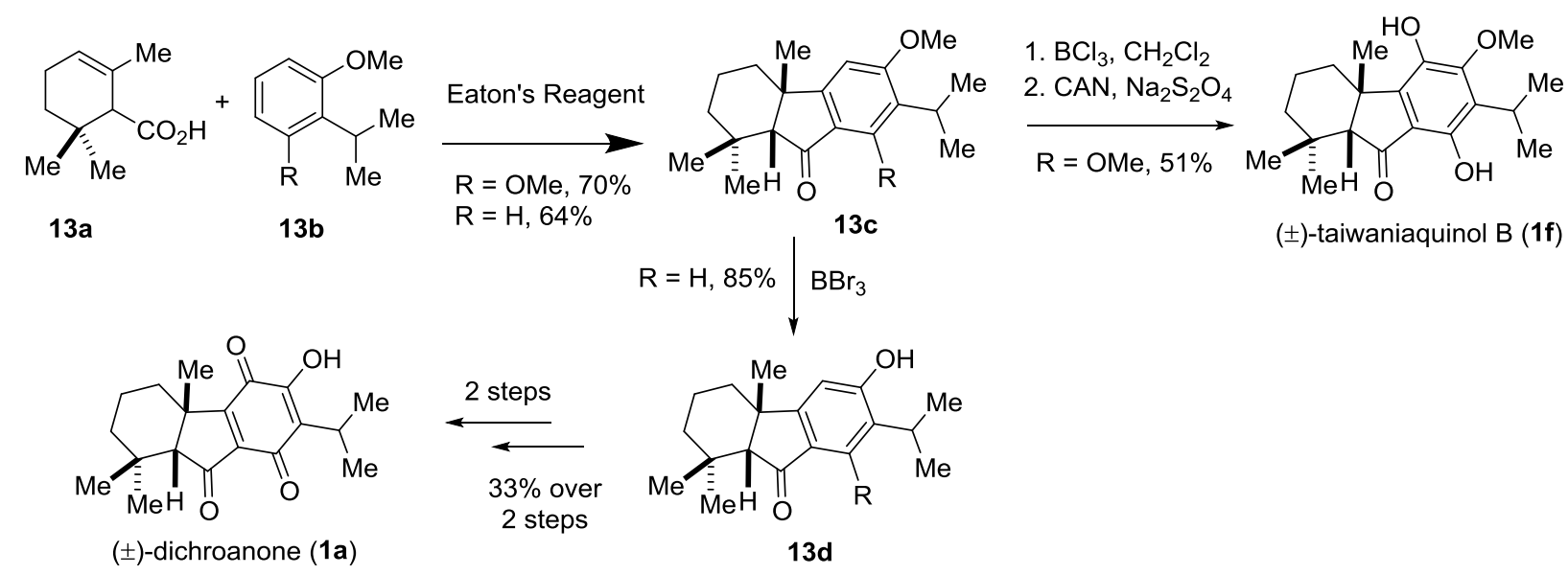

Scheme 8. Domino Friedel-Craft acylation/alkylation by She (2008).

In 2009, Majetich and co-worker, ${ }^{38}$ have reported efficient Nazarov cyclization of arylvinyl ketone $\mathbf{1 4 b}$ strategy for efficient synthesis of carbotricyclic ketone 14c (Scheme 9). The required arylvinyl ketone 14b was synthesized from bromoarene 14a in 2 steps by reacting with $\beta$-cyclocitral in $80 \%$ overall yields. Carbotricyclic ketone 14c was converted to ( \pm )-taiwaniaquinol B (1f) in few steps (Scheme 9). Later, ketone 14c was reacted with vinylmagnesium bromide to afford mixture of products, allylcarbinol 14d and styrerne $\mathbf{1 5}$ in $\mathbf{7 5 \%}$ overall yield (Scheme 9). Allylcarbinol 14d was elaborated to the total synthesis of $( \pm)$-taiwaniaquinol $D(\mathbf{1 m})$ via the intermediacy of $14 \mathrm{e}$. On the otherhand, styrerne $\mathbf{1 5}$ was the advanced intermediate for the total synthesis of ( \pm )-dichroanal B (1h).

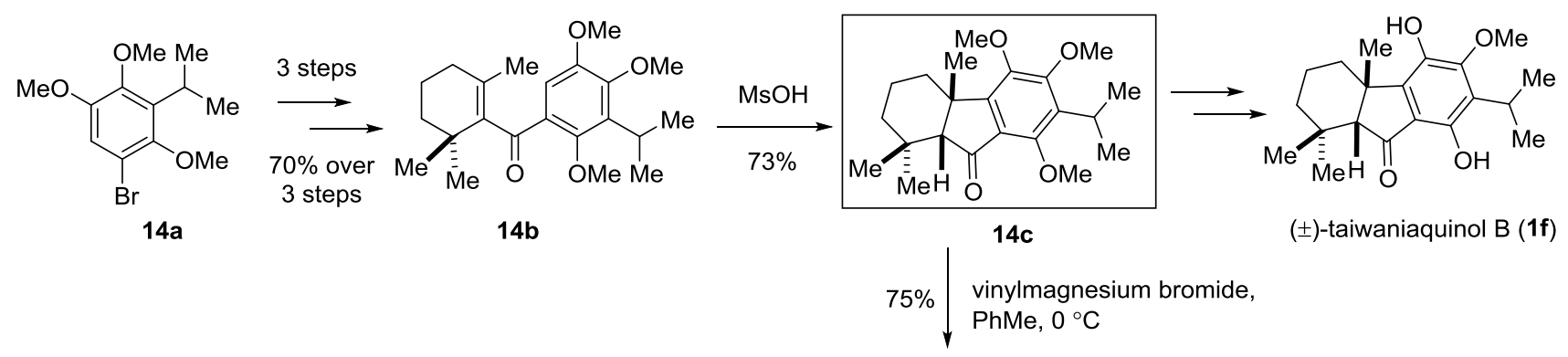

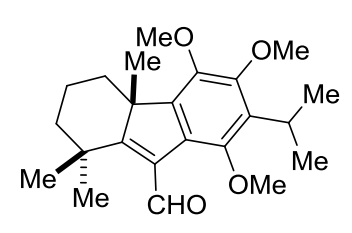

( \pm )-taiwaniaquinol D (1 m)

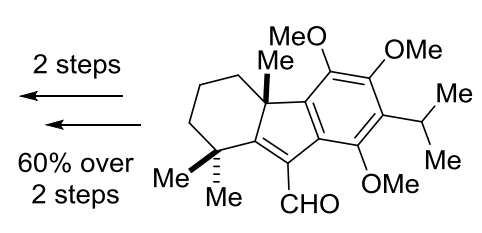

14e

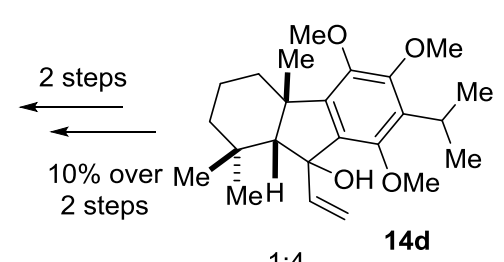

$1: 4$

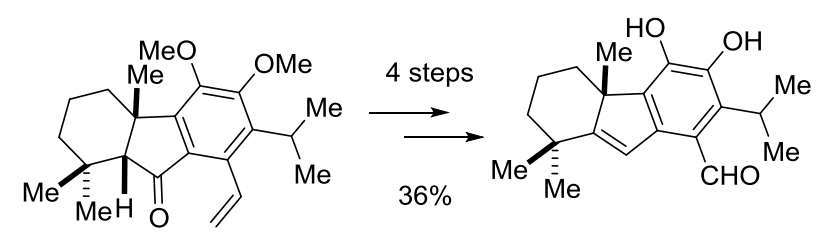

15

( \pm )-dichroanal B (1h)

Scheme 9. Synthetic strategy by Majetich (2009) following a Nazarov cyclization.

In the same year, Alvarez-Manzaneda and co-worker, ${ }^{39}$ have reported effcient Lewis acid-catalyzed cyclization of diene 16c for synthesis of carbotricyclic structure $16 \mathrm{~d}$ in high yield (Scheme 10). The diene 
precursor 16c was synthesized from arylvinyl carbinol 16b, which was synthesized from bromoarene 16a and $\beta$-cyclocitral (10) via a 1,2-addition reaction (Scheme 10). Total syntheses of ( \pm )-dichroanone (1a) and ( \pm )taiwaniaquinone $\mathrm{H}(\mathbf{1 g})$ were synthesized following a strategy shown as per Scheme 10.
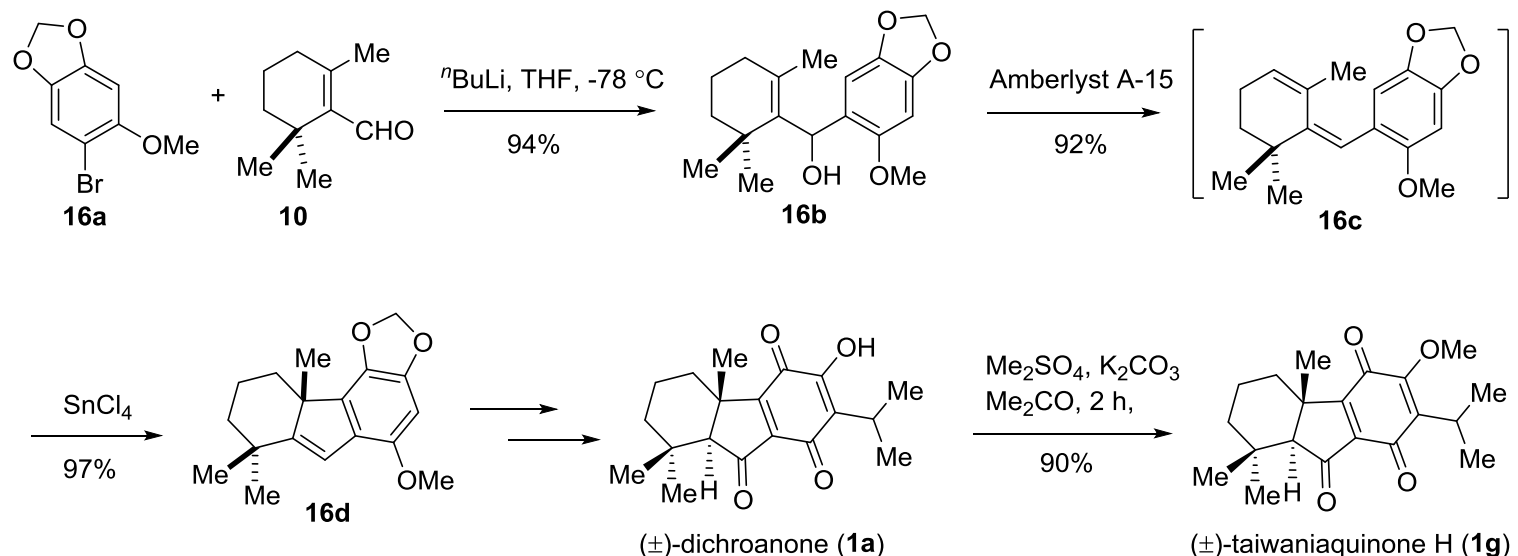

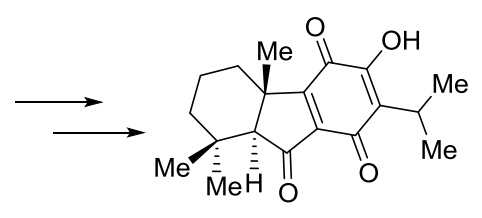

$( \pm)$-dichroanone (1a)

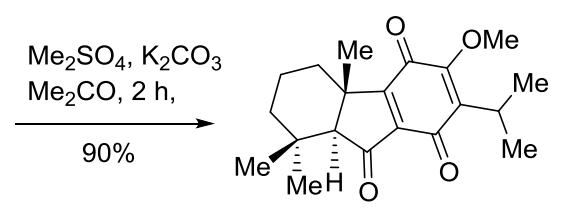

( \pm -taiwaniaquinone $\mathrm{H}(\mathbf{1 g})$

Scheme 10. Lewis acid-catalyzed cyclization of diene by Alvarez-Manzaneda (2009).

In 2013, Li et. al. have developed an efficient route for the divergent total syntheses of ( \pm )taiwaniaquinone $A(\mathbf{1 d}),( \pm)$-taiwaniaquinone $F(\mathbf{1 e}),( \pm)$-taiwaniaquinol $B(\mathbf{1 f})$ and $( \pm)$-taiwaniaquinol $D(\mathbf{1} \mathbf{m})$ via a key Wolff type ring contraction reaction of a trans-fused $[6,5,6]$-ring system (Scheme 11$).{ }^{40}$ The reaction of adehyde 17a (prepared from commercially available 1,2,4-trimethoxybenzene in 4 steps ${ }^{41}$ ) with methylenetriphenylphosphorane furnished styrene, which was hydroborated with 9-BBN to afford the corresponding alkylborane. ${ }^{41,42,43}$ This in situ generated borane was subjected to Suzuki-Miyaura coupling ${ }^{43}$ in the presence of alkenyl iodide $17 b$ to afford $17 \mathrm{c}$ in $83 \%$ yield from aldehyde 17a (Scheme 11). Treatment of 17c with 10 mol\% $\mathrm{Bi}(\mathrm{OTf})_{3}$ provided tricyclic compound in $71 \%$ yield with a trans-A/B ring junction, which was oxidized at benzylic position to provide $\mathbf{1 7 d}$ in $89 \%$ yield. Ketone $\mathbf{1 7 d}$ was then converted to $\alpha$-diazoketone 17 in $78 \%$ yield by treatment of $\mathrm{TrisN}_{3}$ and $\mathrm{Bu}_{4} \mathrm{NOH}$. Wolff rearrangement of $17 \mathrm{e}^{44,45}$ afforded benzyl ester $\mathbf{1 7 f}$ as a single detectable diastereomer in $56 \%$ yield (Scheme 11 ).

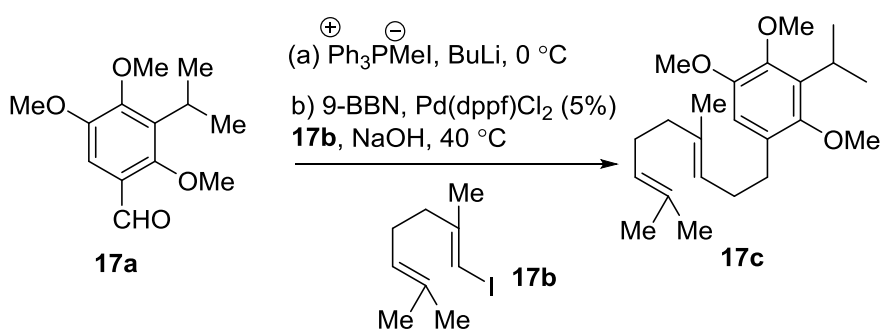

(a) $10 \mathrm{~mol} \% \mathrm{Bi}(\mathrm{OTf})_{3}$ (b) $\mathrm{A}, \mathrm{CrO}_{3},-10^{\circ} \mathrm{C}$
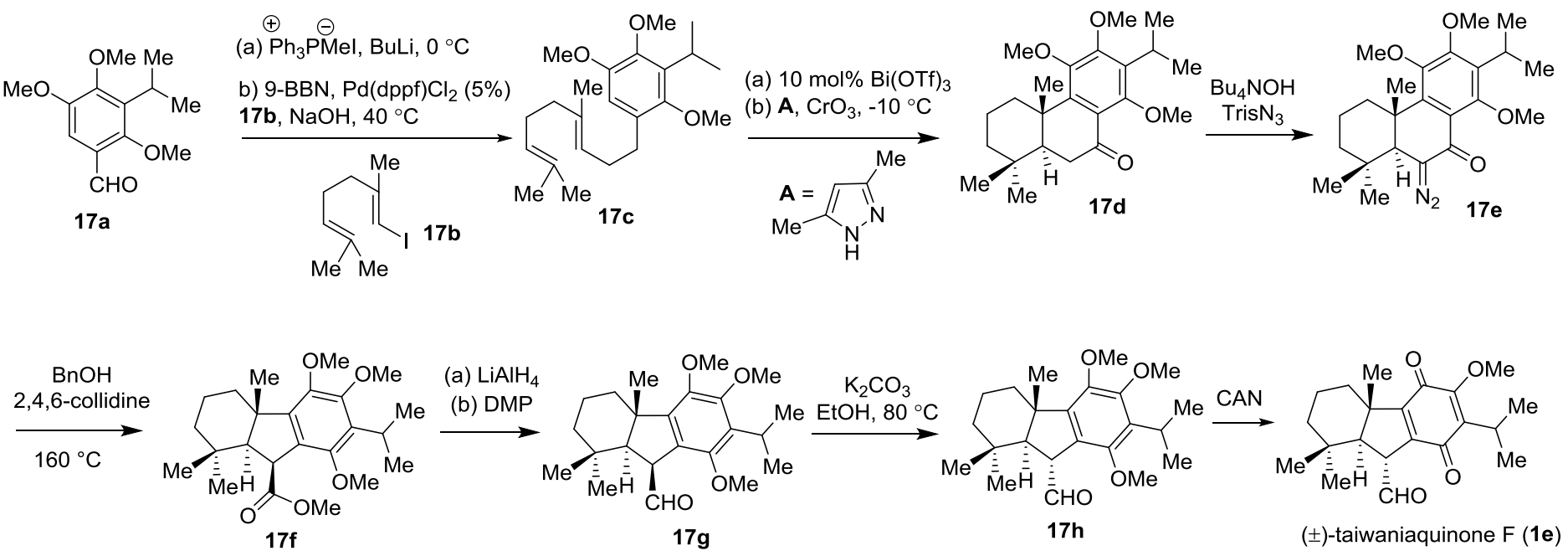

Scheme 11. Total syntheses of taiwaniaquinoids by Li (2013). 
Reduction of ester $\mathbf{1 7 f}$ followed by oxidation with Dess-Martin periodione furnished aldehyde $\mathbf{1 7 g}$ in $\mathbf{7 5 \%}$ yield over 2 steps, which was epimerize to furnish 17h (Scheme 11). Compound 17h was reacted with excess of $\mathrm{BBr}_{3}$ followed by aerobic oxidation completed total synthesis of $( \pm$ )-taiwaniaquinone $\mathrm{A}(\mathbf{1 d})$ in $76 \%$ yield. Intermediate $17 \mathrm{~h}$ was oxidized with CAN to afford $( \pm)$-taiwaniaquinone $F(1 \mathrm{e})$ in $76 \%$ yield. In another direction, treatment of $\mathbf{1 7 g}$ with TMSOTf and $\mathrm{Et}_{3} \mathrm{~N}$ gave silyl enol ether $\mathbf{1 7 i}$ (ca. 1.2:1 cis/trans isomers), which underwent a sequence of Saegusa-Ito oxidation, ${ }^{46}$ monodemethylation, and one-pot oxidation/reduction to afford ( \pm )-taiwaniaquinol $\mathrm{D}(\mathbf{1 m})$. Further, dihydroxylation of 17i using $\mathrm{K}_{2} \mathrm{OsO}_{2}(\mathrm{OH})_{4}$ and $\mathrm{NMO}$ afforded ketone 17j, from which total synthesis of ( \pm )-taiwaniaquinol $B(\mathbf{1 f})$ was obtained in $81 \%$ overall yield (Scheme 12).

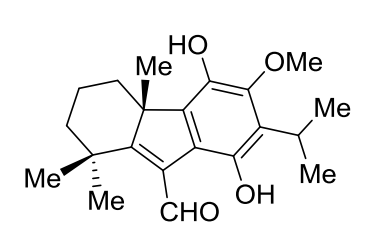

( \pm )-taiwaniaquinol D (1 $\mathbf{m})$

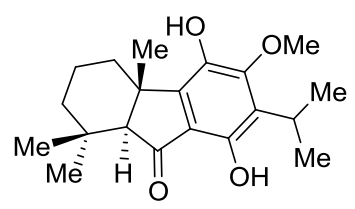

(士)-taiwaniaquinol B (1f)

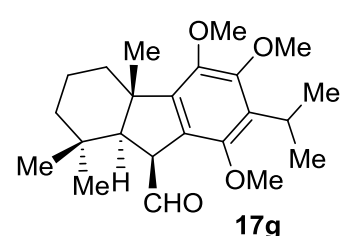

TMSOTf, Et ${ }_{3} \mathrm{~N}$

$\mathrm{Pd}(\mathrm{OAc})_{2}, 65^{\circ} \mathrm{C}$ $\mathrm{BBr}_{3},-78^{\circ} \mathrm{C}$ CAN; $\mathrm{Na}_{2} \mathrm{SO}_{4}$
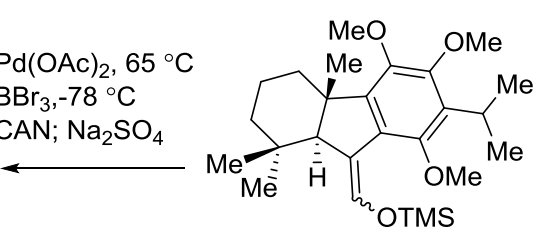

$17 \mathbf{i}$

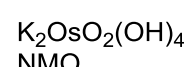
$\mathrm{NMO}$
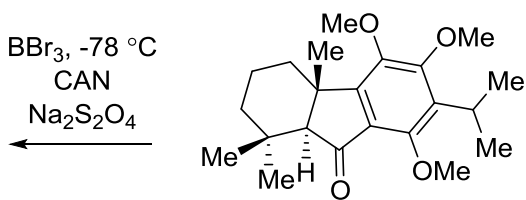

$17 \mathrm{j}$
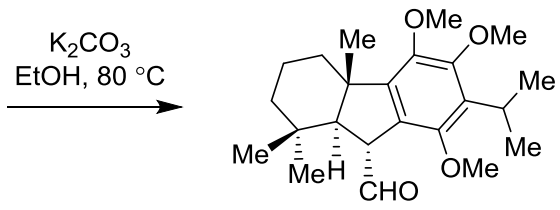

17h
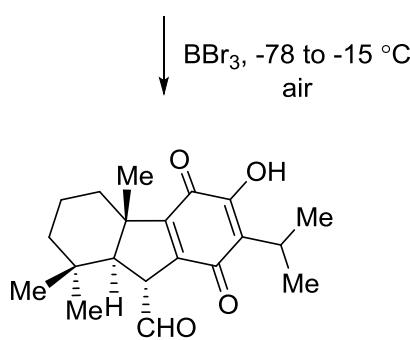

( \pm )-taiwaniaquinone $A(\mathbf{1 d})$

Scheme 12. Collective Total syntheses by Li and co-workers (2013).

In 2014, Hu and Yan reported protecting group-free total synthesis of ( \pm )-taiwaniaquinone $\mathrm{H}(\mathbf{1 g})$ via a key

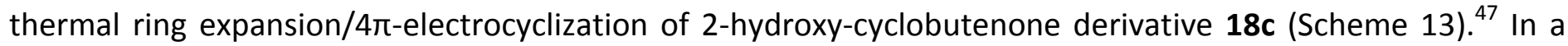
synthetic sequence, cyclobutenedione $\mathbf{1 8 b}$ was prepared in $90 \%$ yield from dimethyl squarate $18 \mathrm{a}$ and isopropylmagnesium bromide following Moore's established protocol. ${ }^{48}$ Ethynylmagnesium bromide was added to commercially available $\beta$-cyclocitral 10 at $-30{ }^{\circ} \mathrm{C}$, which was subsequently treated with ${ }^{t} \mathrm{BuLi}$ and cyclobutenedione $\mathbf{1 8 b}$ sequentially to afford $\mathbf{1 8 c}$ in $39 \%$ yield in a one-pot fashion. ${ }^{49}$ Thermal ring $^{2}$

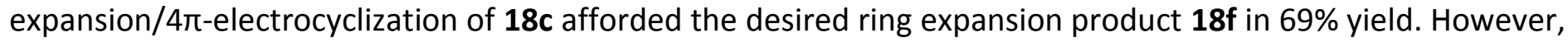
when the reaction was carried out in the presence of $\mathrm{TiCl}_{4}$, the expected thermal ring expansion/4 $\pi$ electrocyclization process afforded $( \pm)$-taiwaniaquinone $\mathrm{H}(\mathbf{1 g})$ in $41 \%$ yield from $\mathbf{1 8 c}$. 

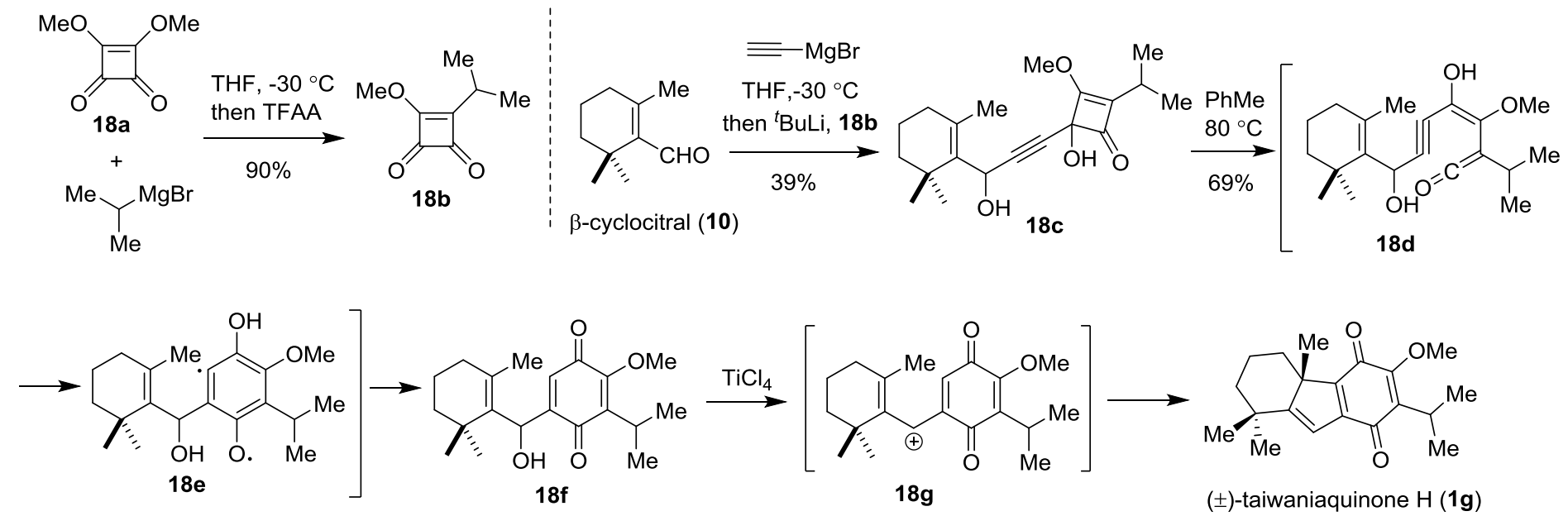

Scheme 13. Total synthesis of $( \pm)$-taiwaniaquinone $H(\mathbf{1 g})$ by Hu and Yan.

In 2015, Bisai et. al. have reported first total synthesis of ( \pm )-taiwaniaquinol $F(\mathbf{1 k})$, sharing an oxidized Aring (Scheme 14). ${ }^{50,51}$ This synthesis began with Lewis acid-catalyzed cyclization of aryl divinylcarbinol 19 a to afford carbotricyclic core 19c with two olefin functionality via the intermediacy of diallylcarbocation 19b (Scheme 14). Compound 19a was prepared in one step via 1,2-addition of known bromoarene onto commercially available safranal. ${ }^{50}$ Allylic oxidation of $19 \mathrm{c}$ with $\mathrm{SeO}_{2}$ afforded allylalcohol $19 \mathrm{~d}$ as single diastereomer in $83 \%$ yield. Excellent diastereoselectivity of allylic oxidation of 19c was attributed because of oxidation taken place from less hindered convex face. Next, 19d was oxidized to obtain $\alpha, \beta$-unsaturated ketone 19e, which was further hydrogenated to afford tricyclic ketone $19 \mathrm{f}$ in $98 \%$ yield. The later was reacted with $\mathrm{CrO}_{3}$ to affect benzylic oxidation to give $\mathbf{1 9 g}$, from where total synthesis of ( \pm )-taiwaniaquinol $\mathrm{F} \mathbf{1} \mathbf{k}$ was completed in 3 steps viz reaction with $\mathrm{BBr}_{3}$ followed by oxidation using CAN and reduction with $\mathrm{Na}_{2} \mathrm{~S}_{2} \mathrm{O}_{5}$. This strategy was successfully utilized for concise total syntheses of other congeners such as $( \pm)$-dichronanone (1a),

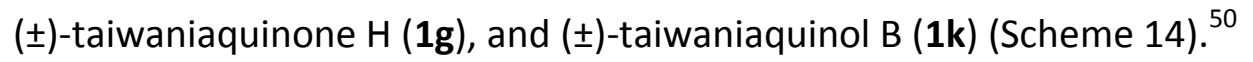

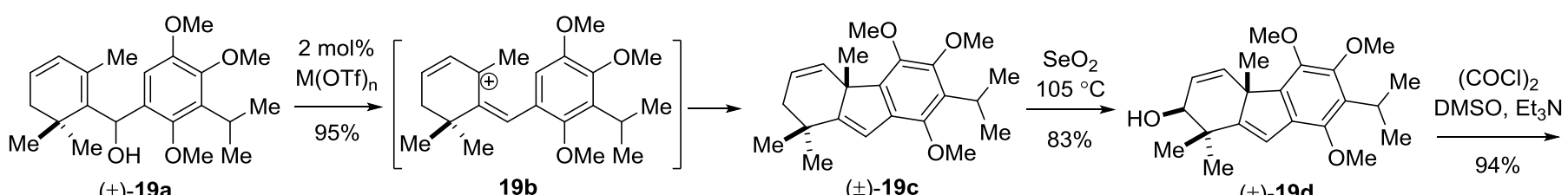

$( \pm)-19 a$

$19 b$

$( \pm)-19 c$

$( \pm)-19 d$

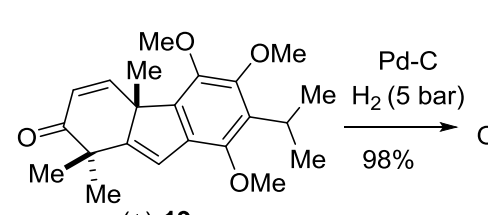

$( \pm)-19 e$

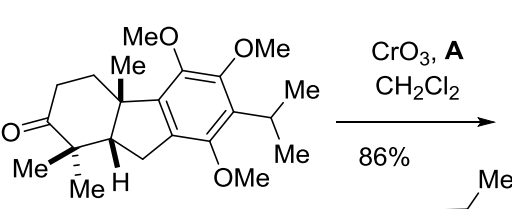

$( \pm)-19 f$

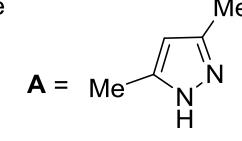

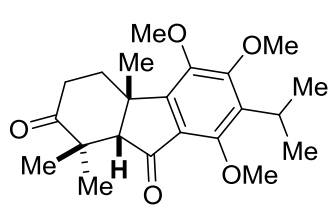

$( \pm)-19 g$

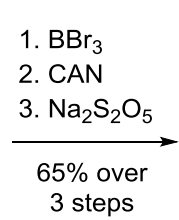

3 steps

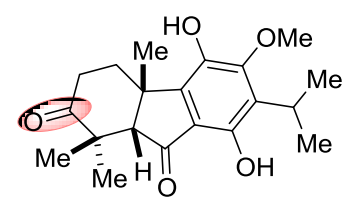

( \pm )-taiwaniaquinol F (1k)

Scheme 14. Total synthesis of ( \pm )-taiwaniaquinol $F(\mathbf{1 k})$ by Bisai.

In 2016, Bisai et. al. have reported total syntheses of naturally ocurrring abeo-abietane diterpenoids, ( \pm )taiwaniaquinone $D(\mathbf{1 s})$ and $( \pm)$-taiwaniaquinol $D(\mathbf{1 m}) .^{52}$ In a synthetic sequence, carbotricyclic core $22 \mathrm{a}$ (which was prepared from a Nazarov type cyclization of $\mathbf{2 0}$ via the intermediacy of diene 21) was completely 
hydrogenated in presence of $10 \% \mathrm{Pd}-\mathrm{C}$ under $1 \mathrm{~atm}$ pressure of $\mathrm{H}_{2}$ in $\mathrm{MeOH}$ to furnish $23 \mathrm{a}$ in $98 \%$ yield (Scheme 16). Later, 23a was reacted with $\mathrm{CrO}_{3}$ in presence of 3,5-dimethylpyrazole to affect benzylic oxidation to furnish ketone $\mathbf{2 3 b}$ in $\mathbf{9 1 \%}$ yield, which on subsequent reaction with methylmagnesium bromide afforded 23c as single diastereomer in $91 \%$ yield. ${ }^{53}$

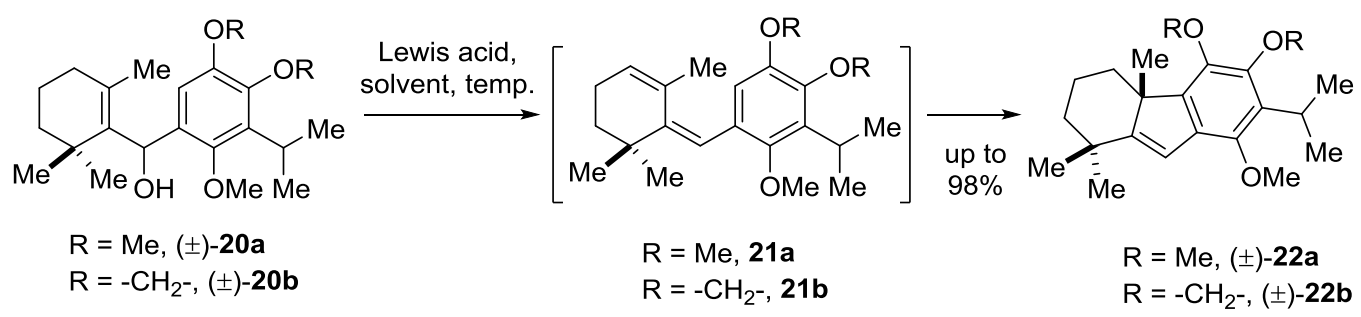

Scheme 15. Optimization of cyclization of arylvinylcarbinol 20a-b.

Later, benzyl alcohol $\mathbf{2 3 d}$ was treated with $\mathrm{BF}_{3} \mathrm{Et}_{2} \mathrm{O}$ leading to the formation of $23 \mathrm{e}$ and $23 \mathrm{f}$ in $2.1: 1$ ratio (Scheme 16), which on subsequent allylic oxidation using $\mathrm{SeO}_{2}$ afforded $24 a$ as an exclusive product. ${ }^{53}$ The later was oxidized under Swern oxidation to furnish $\alpha, \beta$-unsaturated aldehyde $\mathbf{2 4 b}$ in $94 \%$ yield (Scheme 16). Next, compound 24b was treated with $\mathrm{BBr}_{3}$ followed by oxidation using ceric (IV) ammonium nitrate simply afforded potential $p$-quinone intermediate $\mathbf{2 4 c .}$
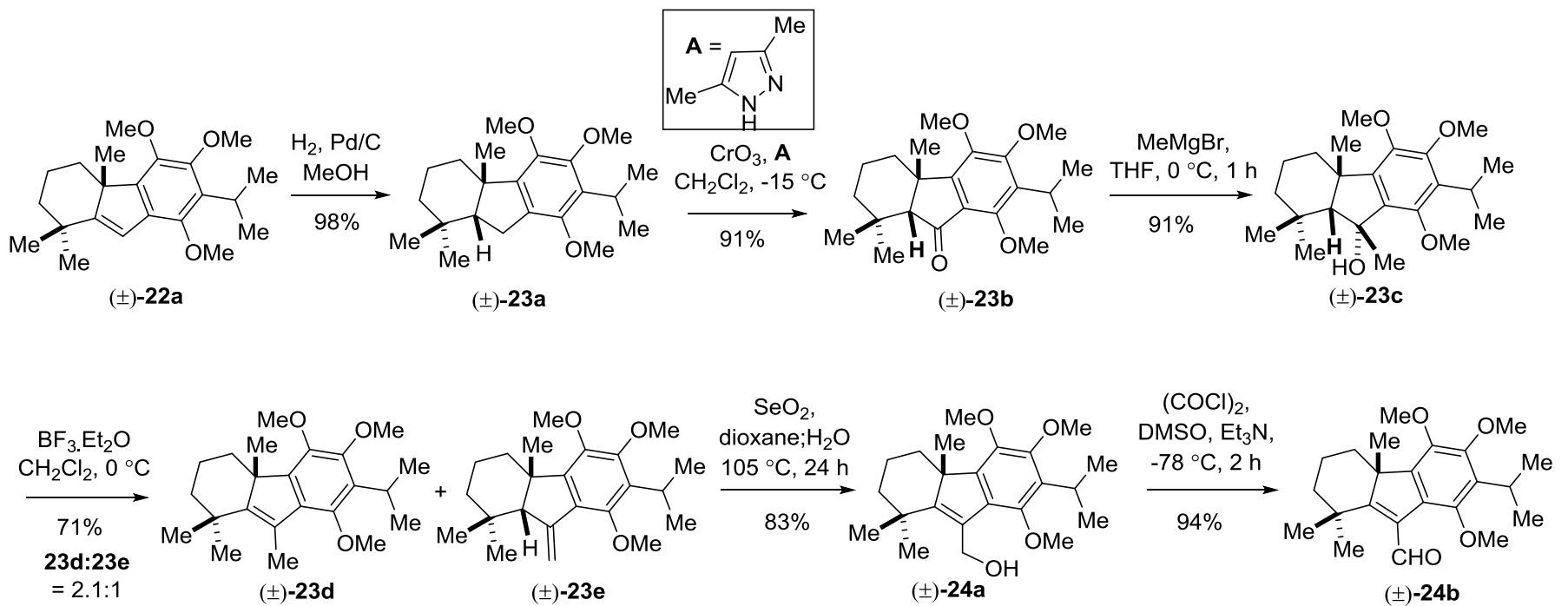

Scheme 16. Synthesis of common precursor $\mathbf{2 4 b .}$

Further, hydrolysis of intermediate $\mathbf{2 4 c}$ in $\mathrm{KOH}$ in $\mathrm{MeOH}$ at room remperature completed total synthesis of $( \pm)$-taiwaniaquinone $D(\mathbf{1 s})$. On the other hand, reduction of $p$-quinone functionality was performed with $\mathrm{Na}_{2} \mathrm{~S}_{2} \mathrm{O}_{4}$ to complete total synthesis of $( \pm$ )-taiwaniaquinol $\mathrm{D}(\mathbf{1 m})$ in $88 \%$ yields (Scheme 17$){ }^{53}$ 


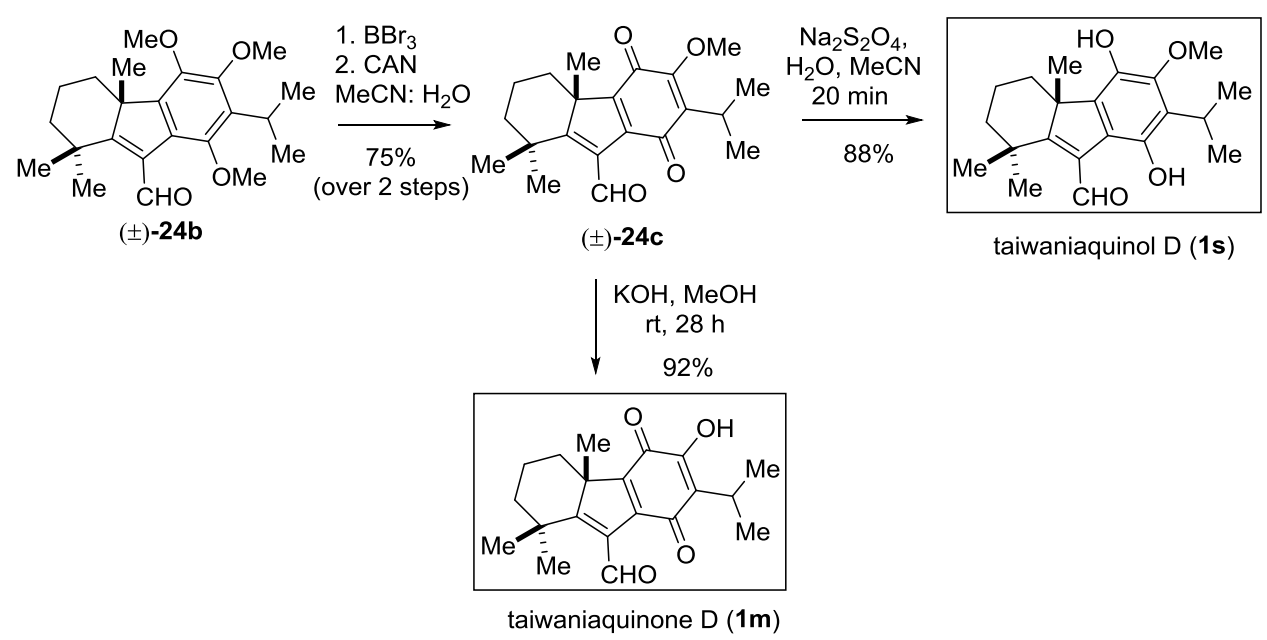

Scheme 17. Total synthesis of $( \pm)$-taiwaniaquinone $D(\mathbf{1 h})$ and $( \pm)$-taiwaniaquinol $D(\mathbf{1 e})$.

Further, the same group have reported total syntheses of taiwaniaquinoids, dichroanal A (1b), dichroanal B (1h) and keto form of caryopincaolide $\mathrm{H}$ (1p) following a key Nazarov type cyclization. ${ }^{53}$ Initially, it was thought to access from a Nazarov type cyclization of arylvinyl carbinol 20c (Scheme 18). However, under the optimized conditions $A$ and $B, \mathbf{2 0 c}$ went through a highly regioselective manner to afford only $\mathbf{2 2 d}$ in $\mathbf{9 7 - 9 8 \%}$ and no traces of $22 \mathrm{c}$ was observed.

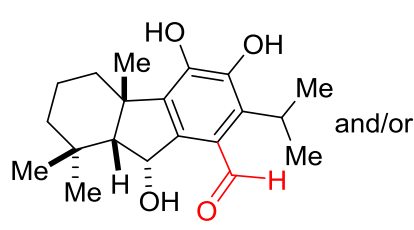

dichroanal A (1b)

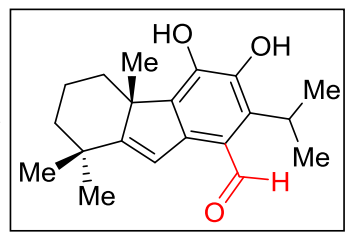

dichroanal B (1h)

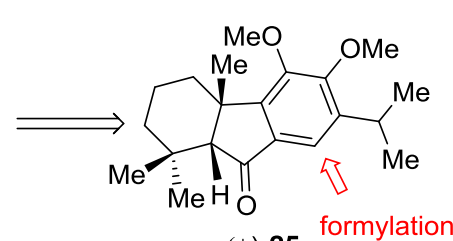

$( \pm)-25$

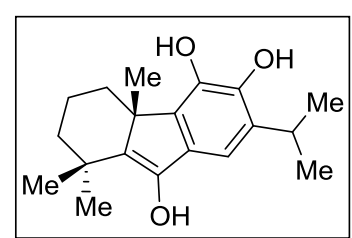

caryopincaolide $\mathrm{H}(\mathbf{1 p})$

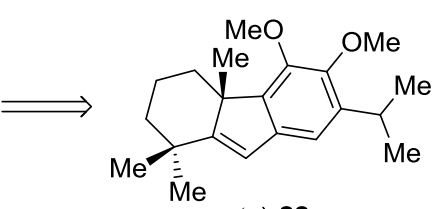

$( \pm)-22 c$

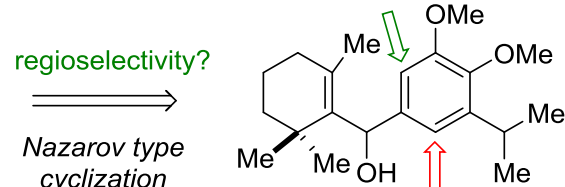

$( \pm)-20 c$

Scheme 18. Retrosynthetic analysis of ( \pm )-dichroanals A (1b) and B (1h).

Compound $\mathbf{2 2 d}$ was converted into bromoarene $\mathbf{2 2 e}$, which afforded suitable single crystal for X-ray analysis (Scheme 19). Therefore, regioisomer $\mathbf{2 2 d}$ was unequivocally proved by X-ray crystal analysis of $\mathbf{2 2 e}$. This reaction clearly indicate that the regioselectivity of Nazarov type reaction is completely governed by electronic nature of aromatic ring, but not the sterics imposed by the bulky i-pr group of arylvinyl carbinol 20c (Scheme 19). 


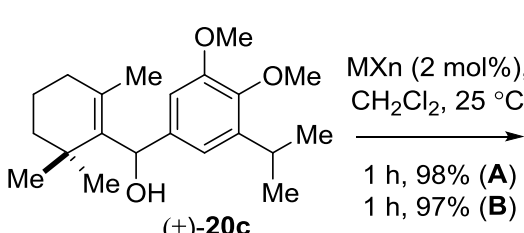

$( \pm)-20 c$

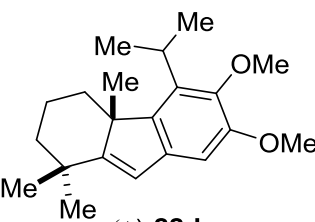

$( \pm)-22 d$

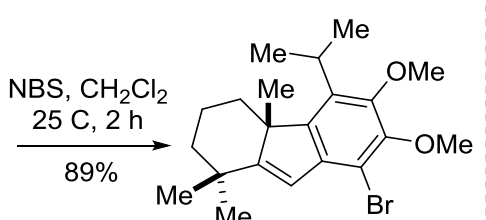

$( \pm)-22 e$

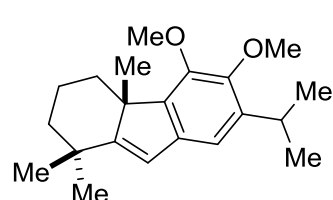

$( \pm)-22 c$

not formed

Scheme 19. Complete regioselectivity using arylvinylcarbinol 20c. [ 2 mol\% of $\mathrm{FeCl}_{3}$ (condition $\mathbf{A}$ ); $2 \mathrm{~mol} \%$ of $\mathrm{SnCl}_{4}$ (condition B)]

Based on the result of Scheme 19, carbotricylic core 26a (prepared from a Nazarov type cyclization of 20d) was envisioned for total synthesis of dichroanal B (1) (Scheme 20). Towards this, hydrogenation of 26a to afford 26b in 99\% yield as sole diastereomer. Next, bromination of 26b in presence of $N$-bromosuccinamide in dichloromethane afforded $\mathbf{2 6}$ in $\mathbf{9 3 \%}$ yield (Scheme 20 ). The later was reacted with sodium methoxide to

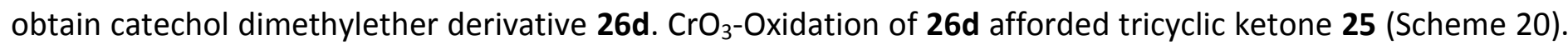
A simple demethylation using $\mathrm{PhSH}$ in the presence of $\mathrm{K}_{2} \mathrm{CO}_{3}$ led to the synthesis of keto form of caryopincaolide $\mathrm{H}$ (1p) in 92\% yield.

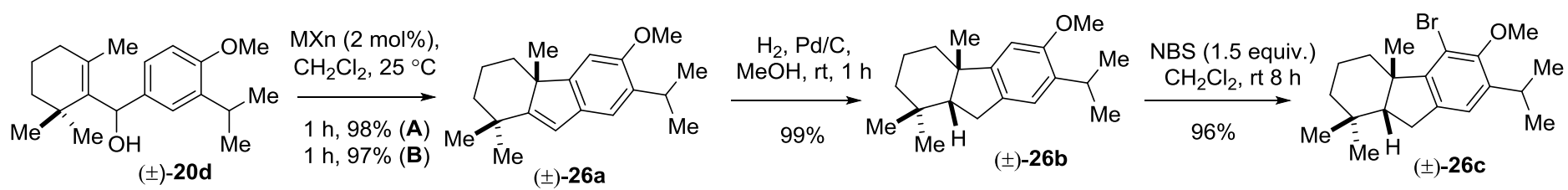

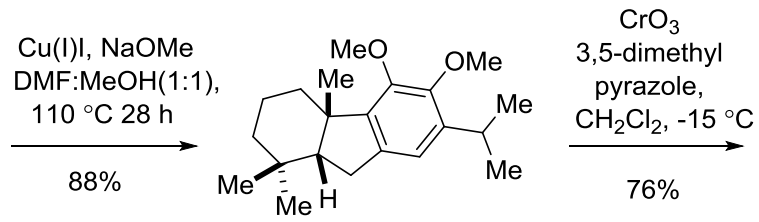

$( \pm)-26 d$

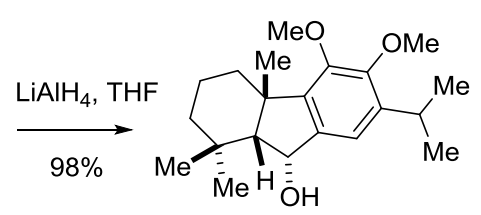

$( \pm)-28 \mathbf{a}$

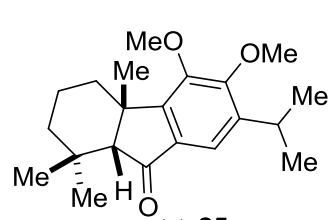

$( \pm)-25$

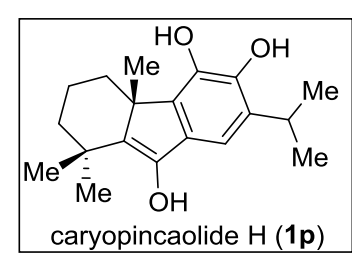

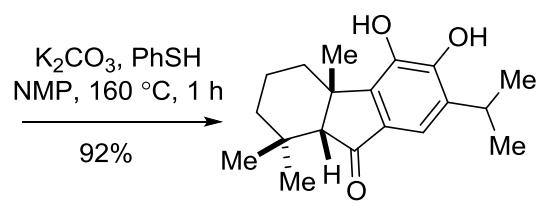

$( \pm)-27$

[keto form of caryopincaolide $\mathrm{H}(1 \mathrm{p})]$

Scheme 20. Synthesis of keto form of $( \pm)$-caryopincaolide $H(\mathbf{1 p})$ and advanced intermediate $( \pm)$-28a.

Later, ketone 27 was reduced to benzyl alcohol 28a in presence of $\mathrm{LiAlH}_{4}$ (Scheme 20). The excellent diastereoselectivity observed in $\mathrm{LiAlH}_{4}$-meidated reaction was attributed to the approach of the hydride from the less hindered convex face of substrate 27. Benzyl alcohol 28a was treated with N-bromosuccinamide, where a one-pot bromination and dehydration led to the formation of $\mathbf{2 8 b}$ in $\mathbf{7 1 \%}$ yield. Finally, total synthesis of $( \pm$ )-dichroanal B (1h) was completed in 2 steps in $87 \%$ overall yield viz. treatment with $n$-BuLi and DMF to form aldehyde $\mathbf{2 8 c}$ followed by demethylation using thiophenol in the presence of $\mathrm{K}_{2} \mathrm{CO}_{3}(\mathrm{Scheme} 21)$. ${ }^{53}$ 


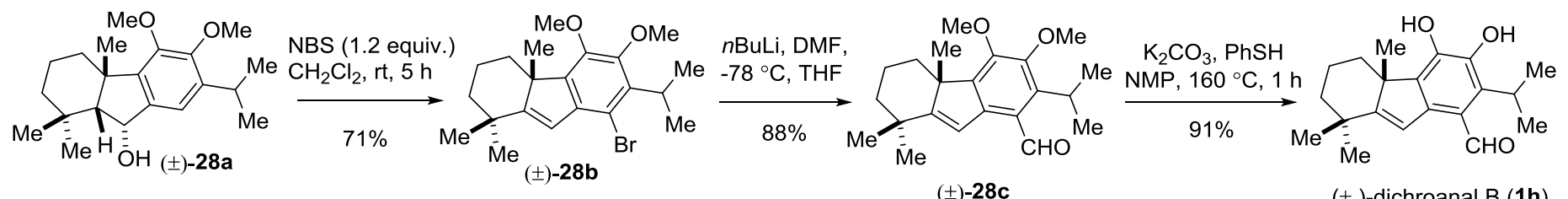

Scheme 21. Total synthesis of $( \pm)$-dichroanal B (1h).

\subsection{Stereocontrolled total syntheses of taiwaniaquinoids}

In the year 2006, Stoltz and co-worker, have reported first enantioselective synthesis of (-)-dichroanone (1a) featuring an enantioselective $\mathrm{Pd}(0)$-catalyzed decarboxylative allylation strategy. ${ }^{54}$ This synthesis takes advantage of a $\mathrm{Pd}(0)$-catalyzed asymmetric allylation methodology to generate all-carbon quaternary centres adjacent to carbonyls. Catalytic enantioselective decarboxylative allylation (DCA) of compound 29b (prepared from 29a by reacting with allylchloroformate) installed the quaternary center in 29c with 91\% ee (Scheme 22). Wacker oxidation ${ }^{55}$ of $29 \mathrm{c}$ followed by condensation provided bicyclic enone $29 \mathrm{e}$ in excellent yield. ${ }^{56}$ Michael addition of the lithium enolate of 29e to methyl vinyl ketone (MVK) formed the keto-enone 29f with high diastereoselectivity. The later was reacted under Robinson annulation strategy followed by reaction with $N$ phenyltriflimide afforded enoltriflate $\mathbf{2 9}$ (Scheme 22). The later was immediately subjected to Kumada coupling with isopropenylmagnesium bromide led to a mixture of isomeric products, which converted irreversibly to compound $\mathbf{2 9 h}$ upon exposure to acid. Later, a formylation of $\mathbf{2 9 h}$ afforded aldehyde $\mathbf{2 9 i}$ in $79 \%$ yield, which was under Baeyer-Villiger sequence installed the first oxygen in 29j (74\% yield). Finally, a one-pot oxidative reaction sequence was followed to complete the synthesis of (+)-dichroanone (1a) under protecting group-free manner.
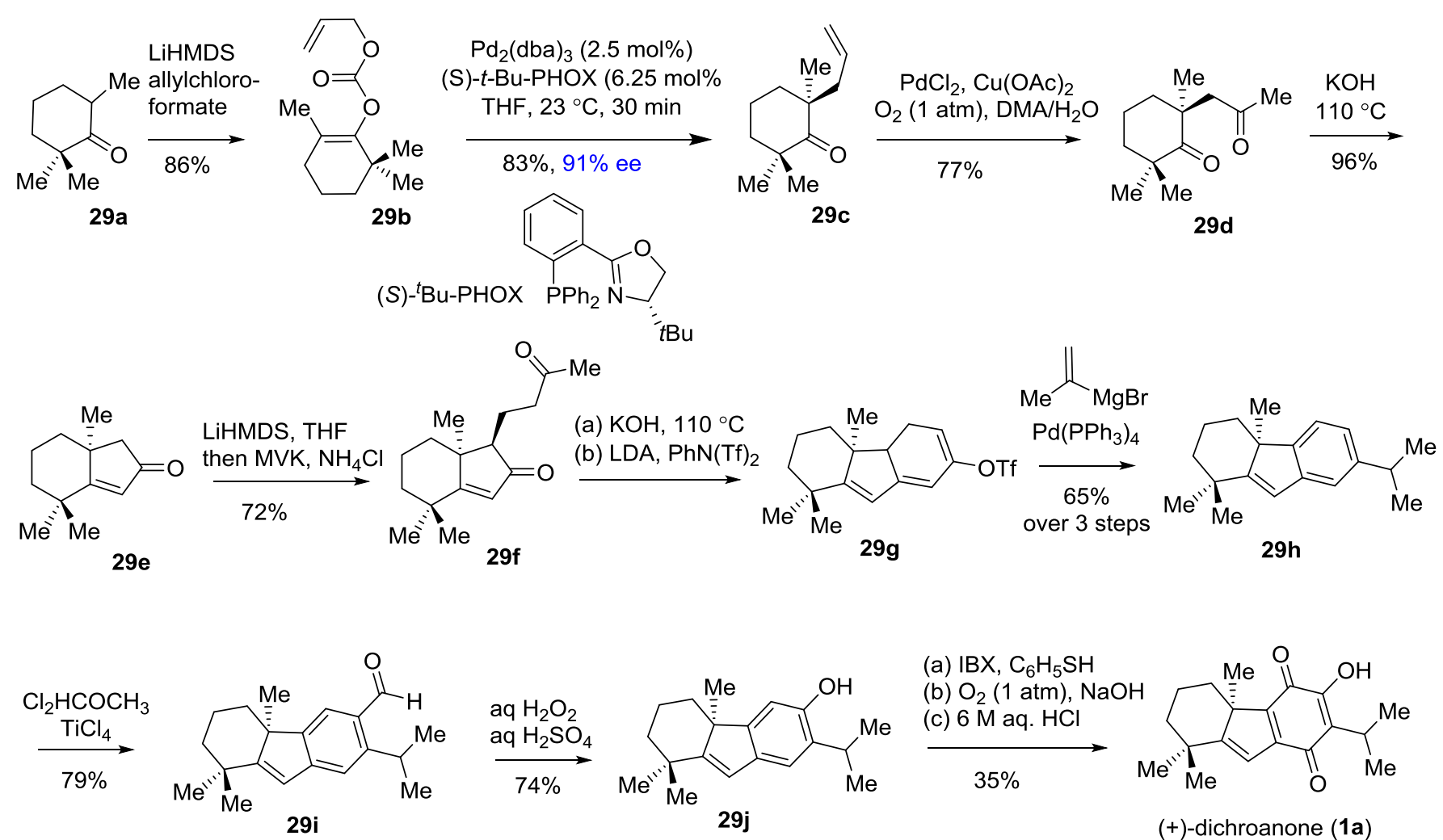

Scheme 22. Total syntheses of (+)-dichroanone (1a) by Stoltz. 
In the year 2009, Alvarez-Manzaneda and co-worker, ${ }^{57,58}$ have reported first enantiospecific synthesis of (-)-taiwaniaquinone $G(\mathbf{1 j})$ from 30c following a key thermal 6 $\pi$-electrocyclization (Scheme 23). From 30c, carbotricyclic enone $\mathbf{3 0 d}$ was synthesized just by heating, which was then elaborated to carbotricyclic structure 30e over 3 steps in $84 \%$ overall yield. Finally, first total synthesis of (-)-taiwaniaquinone G (1j) has been achieved from 30 e in total 5 steps in an overall yield of $74 \%$ (Scheme 23).
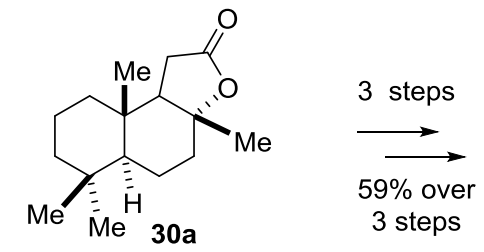

3 steps
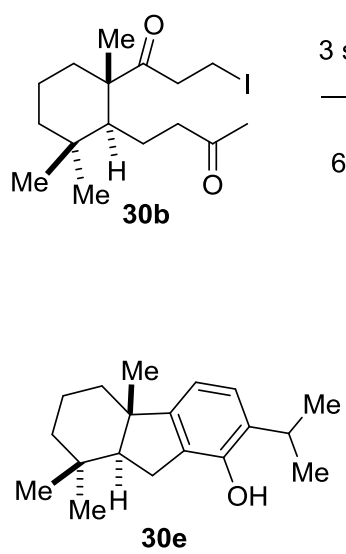
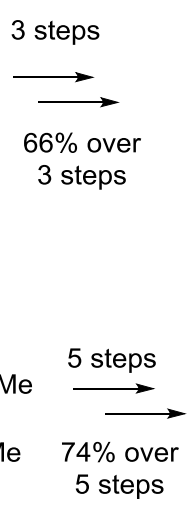
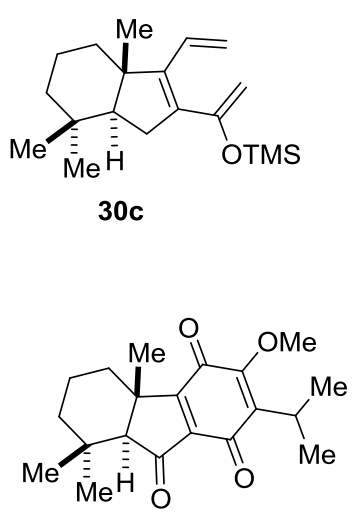

(-)-taiwaniaquinone G (1j)

Scheme 23. Thermal $6 \pi$-electrocyclization by Alvarez-Manzaneda (2009).

In 2010, Node and co-worker have reported asymmetric total syntheses of (-)-dichroanal B (1h), (-)dichroanone (1a), and taiwaniaquinone $\mathrm{H}(\mathbf{1 g})$, by using a catalytic intramolecular asymmetric Heck reaction. 59, 60 They have designed substrate $\mathbf{3 2} \mathbf{b}$ bearing a rigid acetonide group in the catechol moiety, which was prepared by modifying a previously reported method. Commercially available 31a was treated with acetone in the presence of $\mathrm{BF}_{3} . \mathrm{Et}_{2} \mathrm{O}$ to give the acetonide which was under bromination with NBS afforded 31b in excellent yield. After lithiation of the bromide $\mathbf{3 1 b}$ with $n$-butyllithium, the aryllithium generated was reacted with $\beta$-cyclocitral (10) to afford the benzylic alcohol 32a. Dehydration of 32a by treatment with methanolic hydrochloric acid gave the diene as a mixture of $E$ and $Z$ isomers (ca. 1:4), which after demethylation and subsequent triflation afforded required diene $\mathbf{3 2 b .}$

The intramolecular asymmetric Heck reaction of triflate $\mathbf{3 2 b}$ (a mixture of $E / Z$ isomers) in the presence of palladium(II) acetate, (R)-BINAP (34a) afforded 33 in 77\% ee (Scheme 24). Following exhaustive optimization, it was found that the Heck reaction of triflate $\mathbf{3 2 b}$ and successive hydrogenation gave $\mathbf{3 3}$ in good yield ( $<86 \%$ in 2 steps) with excellent ee (94-98\%ee) when ( $R$ )-Synphos (34b) was used. Later, the acetonide of $\mathbf{3 3}$ was subjected to deprotection with $\mathrm{HCl}-\mathrm{MeOH}$ followed by a reaction with dichloromethoxymethane in the presence of $\mathrm{BCl}_{3}$ completed total synthesis of (-)-dichroanal B $\mathbf{1 h}$. Further treatment of 33 with $\mathrm{N}$ bromosuccinimide followed by reaction with sodium methoxide in the presence of Cul followed by removal of the acetonide and oxidation with DDQ afforded total synthesis of (-)-dichroanone A (1a). Finally, the later was reacted with the Meerwein reagent to complete total synthesis of (-)-taiwaniaquinone $\mathrm{H}$ (1g) (Scheme 24).

In 2010, Alvarez-Manzaneda and co-worker, ${ }^{21,61}$ have reported semisynthesis of taiwaniaquinone $A$ (1d) and $F(1 e)$ from abieatic acid (Scheme 25). A new strategy for synthesizing taiwaniaquinoids, based on the cleavage of the C7-C8 double bond of abietane diterpenes is described in this strategy. This procedure is the only one reported for synthesizing $C_{20}$ taiwaniaquinoids bearing a carbon function on the cyclopentane $B$ ring, such as taiwaniaquinone $A(\mathbf{1 d})$ and $F(\mathbf{1 e})$, and it is also applicable to the synthesis of 4amethyltetrahydrofluorene derivatives, such as taiwaniaquinone $\mathrm{H}$ (1g) and dichroanone (1a), and 
4amethylhexahydrofluorene derivatives, having an A/B trans-fused system, such as taiwaniaquinone $G$ (1j), or an $A / B$ cis-fused union, such as taiwaniaquinol $B$ (1).
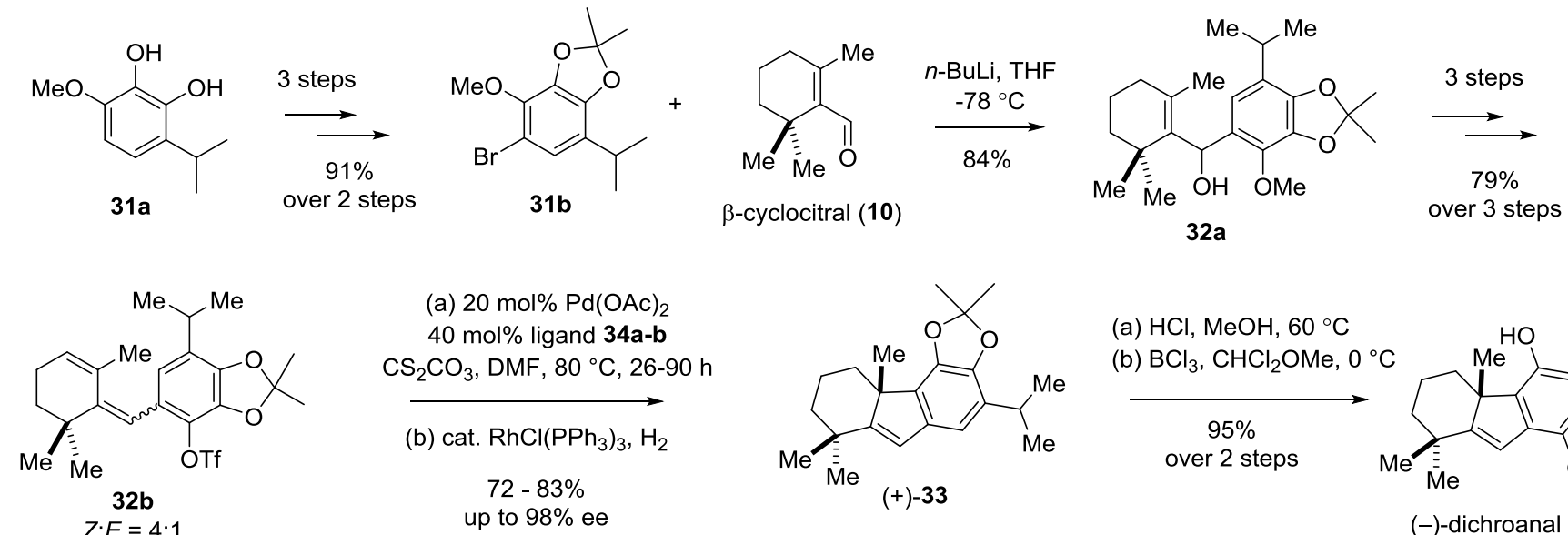

(a) $20 \mathrm{~mol} \% \mathrm{Pd}(\mathrm{OAc})_{2}$

40 mol\% ligand $34 a-b$ $\mathrm{CS}_{2} \mathrm{CO}_{3}$, DMF, $80{ }^{\circ} \mathrm{C}, 26-90 \mathrm{~h}$

(b) cat. $\mathrm{RhCl}\left(\mathrm{PPh}_{3}\right)_{3}, \mathrm{H}_{2}$

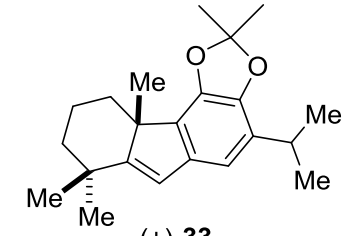

$(+)-33$ (a) $\mathrm{HCl}, \mathrm{MeOH}, 60^{\circ} \mathrm{C}$

(b) $\mathrm{BCl}_{3}, \mathrm{CHCl}_{2} \mathrm{OMe}, 0^{\circ} \mathrm{C}$

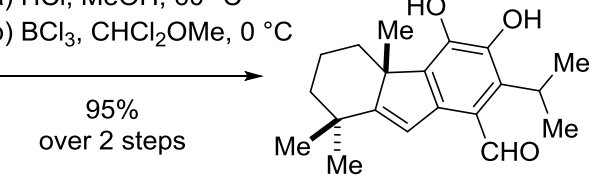

(-)-dichroanal B (1h)

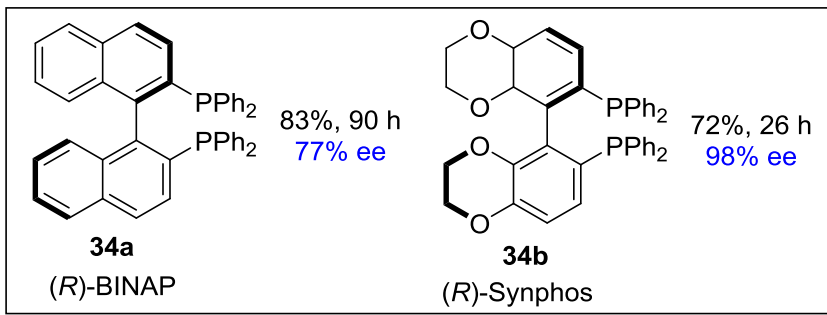

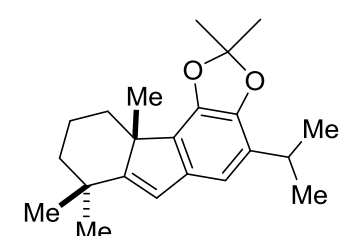

$(+)-33$ (a) NBS, $\mathrm{CH}_{2} \mathrm{Cl}_{2}$

(b) $\mathrm{Cul}, \mathrm{NaOMe}$,

$\underset{95 \%}{\mathrm{DMF}, 100{ }^{\circ} \mathrm{C}}$

over 2 steps

(1)

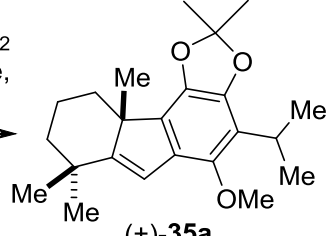

$(+)-35 a$

(a) $\mathrm{BBr}_{3}, \mathrm{CH}_{2} \mathrm{Cl}_{2}$ (b) $\mathrm{DDQ}, \mathrm{CH}_{2} \mathrm{Cl}_{2}$

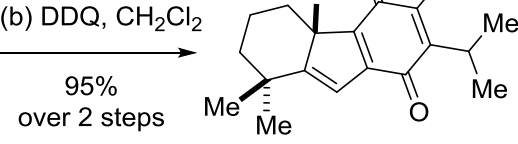

(-)-dichroanone (1a)

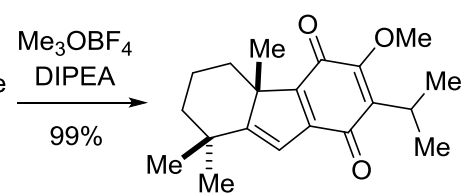

(-)-taiwaniaquinone $\mathrm{H}(\mathbf{1 g})$

Scheme 24. Asymmetric total syntheses by Node via an intramolecular Heck strategy (2010).

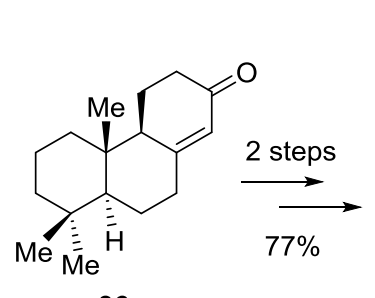

$36 a$

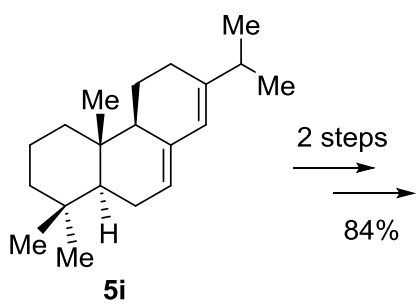

$5 \mathbf{i}$

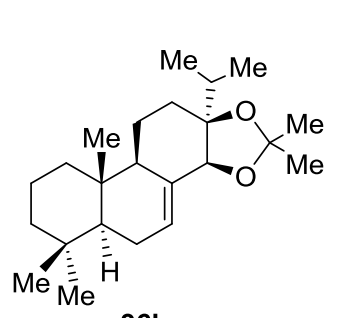

$36 \mathrm{~b}$

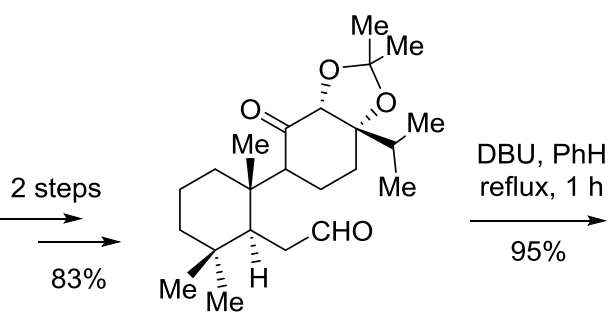

$5 j$

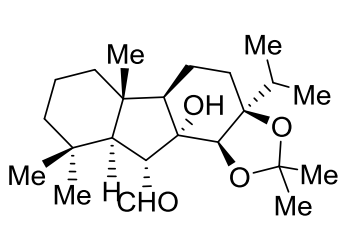

$5 k$
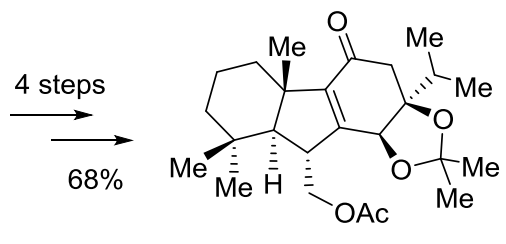

$36 c$
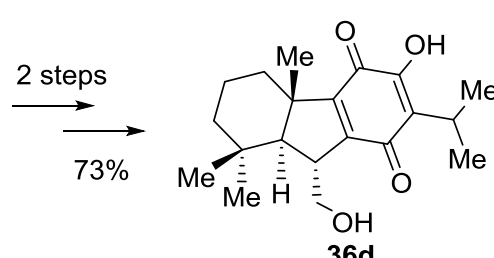

36d

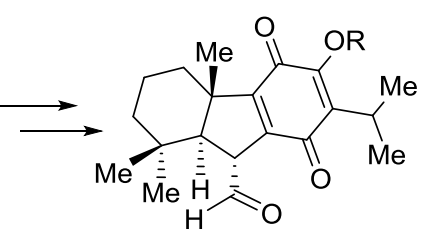

$\mathrm{R}=\mathrm{H}$, taiwaniaquinone $\mathrm{A}(\mathbf{1 d})$ $\mathrm{R}=\mathrm{Me}$, taiwaniaquinone $\mathrm{F}(\mathbf{1 e})$

Scheme 25. Semisynthesis of taiwaniaquinoids by Alvarez-Manzaneda (2010). 
In 2010, Gademann reported a biogenetic hypothesis for the transformation of an abietane-type diterpene into the 6-5-6 skeleton of the taiwaniaquinoids by a ring contraction of an oxidized precursor (Scheme 26). ${ }^{19,20}$ The overall hypothesis of this strategy is summarized in Scheme 26, which was utilized for the total synthesis of (+)-taiwaniaquinone $\mathrm{H}(\mathbf{1 g})$ under protecting group-free condition.

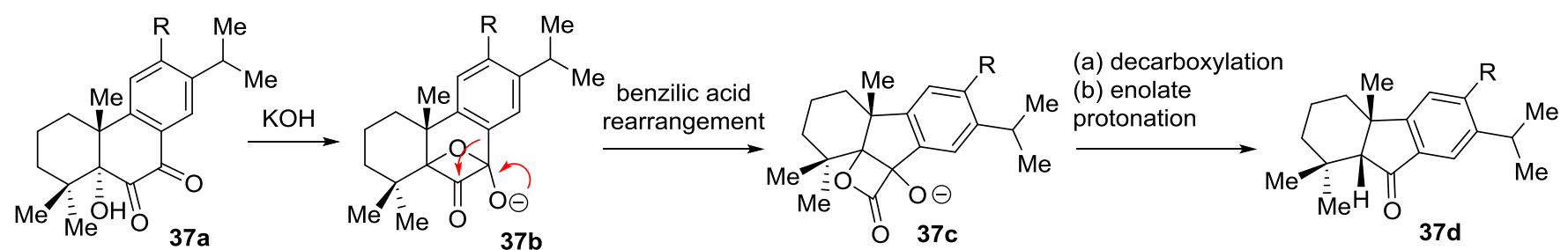

Scheme 26. Hypothesis of conversion of abietane (37a) to abeo-abietane (37d) by Gademann.

The starting material 38a was obtained from commercially available methyl dehydroabiate in 5 steps. ${ }^{62,63}$ The hydroxydiketone functionality of the key intermediate $\mathbf{3 8 b}$ was installed through a Sharpless asymmetric dihydroxylation reaction ${ }^{64}$ (Scheme 27). Treatment of the hydroxydione $\mathbf{3 8 b}$ with LHMDS gave the hydrofluorene derivative 38c, as per proposal shown in Scheme 26, which was reduced with $\mathrm{NaBH}_{4}$ to afford 38d. Later, a one-pot sequence of hydroxy-group-directed ortho lithiation of the benzylic alcohol $\mathbf{3 8 d},{ }^{65,66}$ and subsequent borylation of the aryl lithium compound and oxidation of the corresponding aryl boronate gave the hydroxylated phenol derivative, which was dehydrated under under acidic conditions to furnish dehydrated phenol 38e in 64\% yield over 2 steps (Scheme 27). The later was then cleanly oxidized using Fremy's salt to the corresponding p-quinone 38f. Electrophilic bromination of the quinone $\mathbf{3 8 f}$ followed by substitution with a methoxy group completed total synthesis of (+)-taiwaniaquinone $\mathrm{H}(\mathbf{1 g})$ in $63 \%$ yield over 3 steps (Scheme 27).
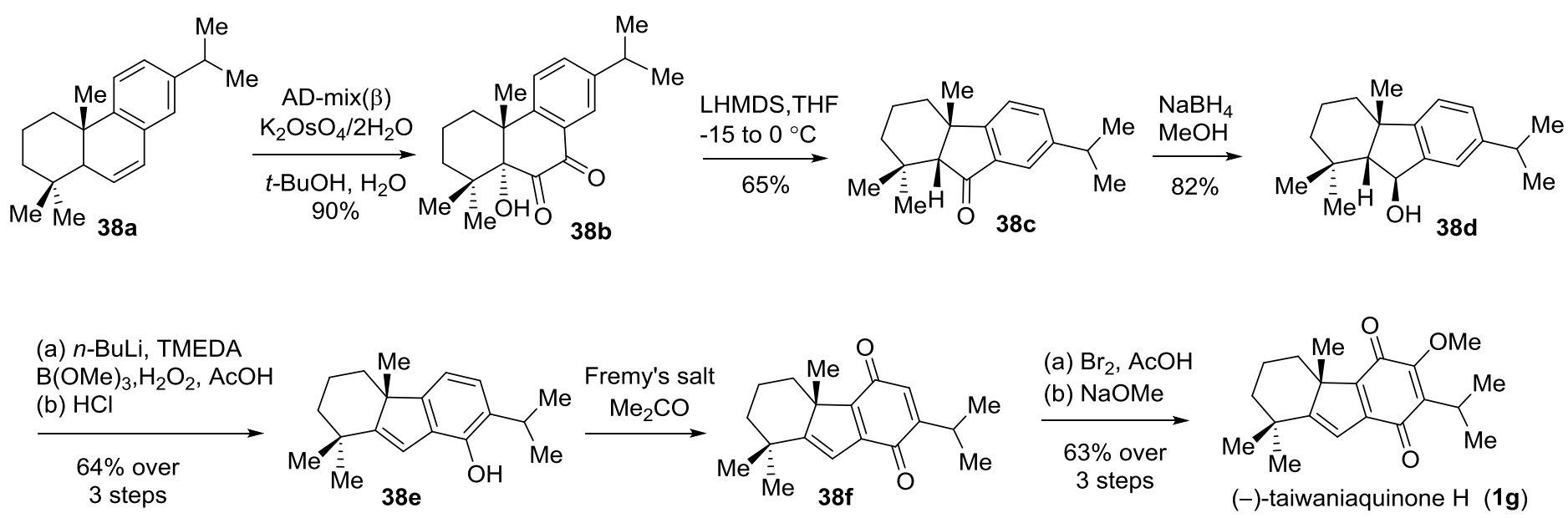

Scheme 27. Total syntheses of (+)-taiwaniaquinone H (1g) by Gademann.

First enantioselective total synthesis of (-)-taiwaniaquinol B (1f) was reported by Hartwig et. al. ${ }^{67}$ The reaction of $39 \mathrm{~b}$ with $39 \mathrm{a}^{68,69}$ in the presence of $\mathrm{Pd}(\mathrm{dba})_{2}$ and $(R)$-Difluorophos (10 mol \%) afforded 39c in $80 \%$ yield with $94 \%$ ee (Scheme 28 ). ${ }^{67}$ 

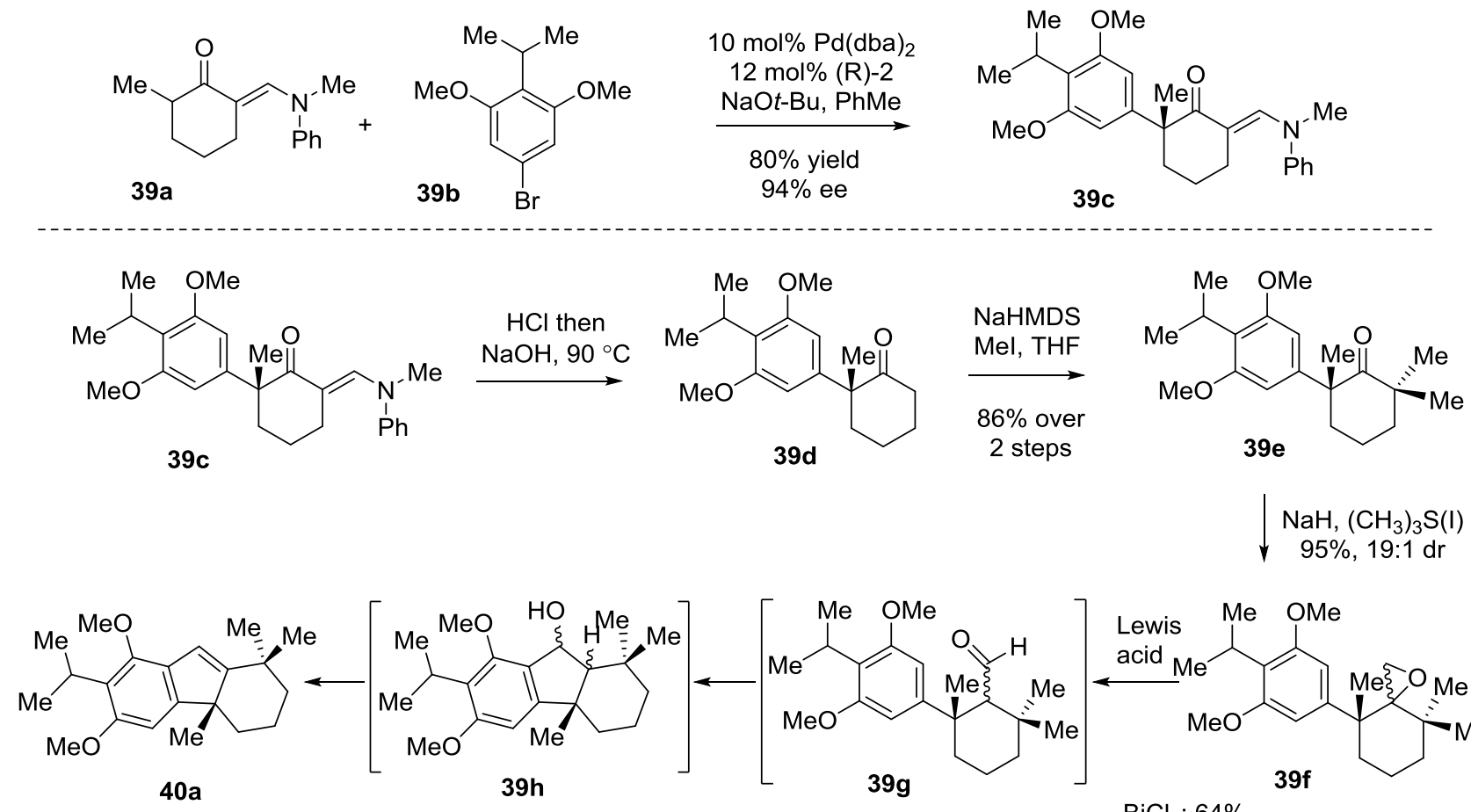

\begin{tabular}{l|l} 
(a) $\mathrm{BH}_{3}$ THF then & $\begin{array}{c}80 \% \text { over } \\
\mathrm{H}_{2} \mathrm{O}_{2}, \mathrm{NaOH} \\
\text { (b) IBX }\end{array}$
\end{tabular}

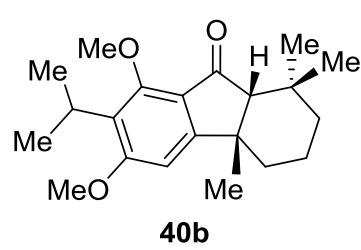

(a) $\mathrm{BCl}_{3}, \mathrm{CH}_{2} \mathrm{Cl}_{2}$
(b) $\mathrm{CAN},{\mathrm{MeCN} / \mathrm{H}_{2} \mathrm{O}}^{\text {(c) } 1 \mathrm{M} \mathrm{Na} \mathrm{S}_{2} \mathrm{O}_{4}}$
$\stackrel{52 \% \text { over }}{2 \text { steps }}$

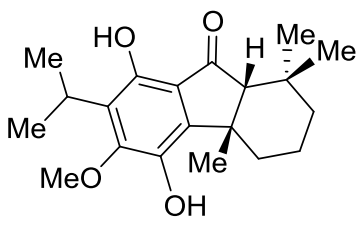

(-)-taiwaniquinol B (1f)

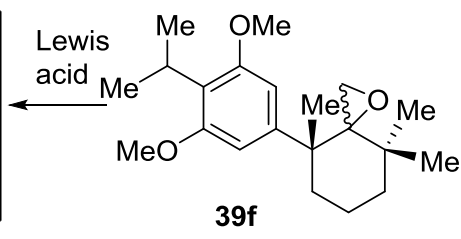

$\mathrm{BiCl}_{3}: 64 \%$

$\mathrm{BF}_{3}$ OEt $_{2}: 50-75 \%$

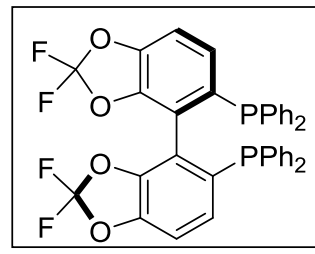

$(R)$ - difluorophos (34c)

Scheme 28. Total syntheses of (-)-taiwaniaquinol B (1f) by Hartwig.

Acid-promoted reaction of ketone 39c provided ketone 39d in 91\% yield over 2 steps. Dimethylation of 39d with methyl iodide using NaHMDS afforded cyclohexanone 39e in $86 \%$ yield. Corey-Chaykovsky epoxidation of ketone 39e using sulfur ylide dimethylsulfonium methylide, ${ }^{70,71,72}$ furnished epoxide 39f in $95 \%$ yield with excellent diastereoselectivity. Later, Lewis acid catalyzed rearrangement of the epoxide 39f to the aldehyde $\mathbf{3 9} \mathrm{g}$ followed by Friedel-Crafts alkylation reaction with $\mathbf{3 9 g}$ afforded corresponding alcohol, which underwent elimination to form the target tetrahydrofluorene 40a. The later under selective monodemethylation followed by oxidation provided (-)-taiwaniaquinone $\mathrm{H}(\mathbf{1 g})$ in $51 \%$ yield over 2 steps (Scheme 6). ${ }^{35}$ Further, hydroboration-oxidation of $40 \mathrm{~b}$ and further oxidation with 2 -iodoxybenzoic acid (IBX) gave $40 \mathrm{a}$ as a single diastereomer. Finally, selective monodemethylation of $\mathbf{4 0 b}$ with $\mathrm{BCl}_{3}$, oxidation with CAN and reductive workup with sodium dithionite gave (-)-taiwaniaquinol B (1) in $52 \%$ yield over 2 steps, as per report by Fillon ${ }^{33}$ and Trauner. ${ }^{35}$

Recently, in 2014, Stoltz and co-workers, ${ }^{73}, 74$ have reported a catalytic, enantioselective formal total

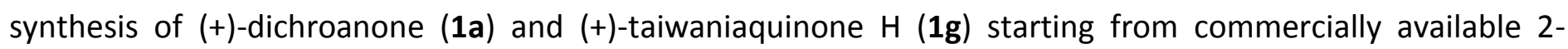
bromoresorcinol (Scheme 29). The required aromatic boronic acid 41b was synthesized from 2bromoresorcinol in few steps. In this strategy, a key all-carbon quaternary stereocenter was constructed in 41c by asymmetric conjugate addition catalyzed by a palladium(II)-(S)-tert-butyl PHOX complex (Scheme 29). This 
cyclohexanone intermediate was further utilized for formal total syntheses of a variety of naturally occurring taiwaniaquinoids.
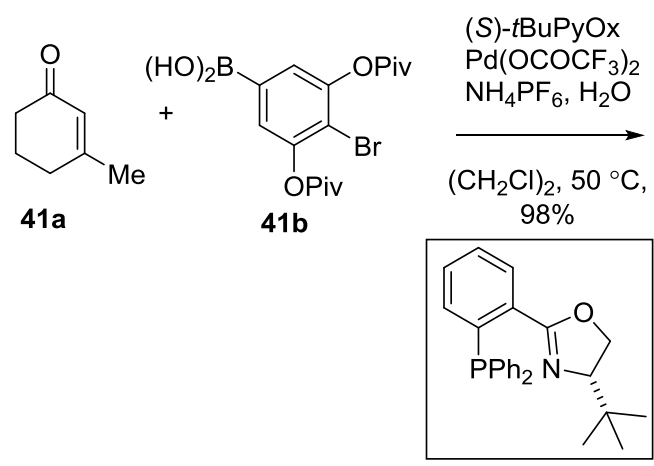
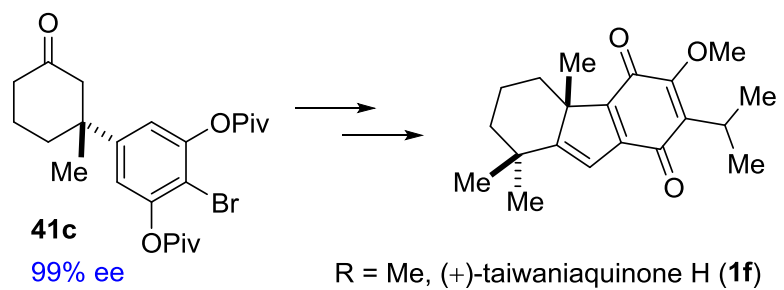

$\mathrm{R}=\mathrm{Me},(+)$-taiwaniaquinone $\mathrm{H}$ (1f) $\mathrm{R}=\mathrm{H},(+)$-dichroanone $(\mathbf{1} \mathbf{a})$

Scheme 29. Pd(II)-Catalyzed enantioselective strategy by Stoltz (2014).

\section{Conclusions}

This review is intended to provide an overview of the complex taiwaniaquinoids where biosynthetic relationship of diterpenoids and synthetic approaches to this family of diterpenoids have been discussed elaborately. The literature on the synthesis of taiwaniaquinoids summarized in this review very well suggest that they have been proposed in the literature to be arisen from abietane diterpenoids. It has been over 23 years since the first member of the abeo-abietane family was isolated in 1995 from the roots of Salvia dichroantha Stapf (Lamiaceae), a Turkish flowering sage. Since that time, an additional twenty abeo-abietanes have been isolated from a variety of plant species from variety of species. The fascinating molecular architecture of the members of this natural product family has stimulated the interest of numerous synthetic chemists which has led to a number of creative synthetic approaches and beautiful total syntheses. Although, the biological activities of only a few numbers of taiwaniaquinoids are reported, the exhaustive biological potential of the majotiry of taiwaniaquinoids has yet to be evaluated. The knowledge from biological stidues would be useful in screening these products for therapeutic applications.

\section{Acknowledgements}

VB sincerely thanks the Science Engineering Research Board (SERB), Department of Science and Technology (DST) [CS-021/2014] for financial support and Department of Chemistry, IISER Berhampur. AB sincerely thanks the SERB, DST, Govt. of INDIA [EMR/2016/000214], the Council of Scientific and Industrial Research (CSIR), Govt. of India [02(0295)/17/EMR-II], and Ministry of Earth Science (MoES), Govt. of India [MoES-2/DS/6/2007 PC-IV] for generous support. Facilities from the Department of Chemistry, IISER Bhopal is gratefully acknowledged.

\section{References and Notes}

1. Terpenes are a diverse class of organic compounds, produced by a variety of plants, particularly conifers, for a review, see; Hanson, J. R. Nat. Prod. Rep. 2013, 30, 1346.

https://doi.org/10.1039/c3np70046a

2. For a recent review on abietane terpenoids, see, Gonzalez, M. A. Nat. Prod. Rep. 2015, 32, 684. https://doi.org/10.1039/C4NP00110A 
3. For an excellent review on taiwaniaquinoids, see; Majetich, G.; Shimkus, J. M. J. Nat. Prod. 2010, $73,284$. https://doi.org/10.1021/np9004695

4. $\quad$ Lin, W. ; Fang, J. ; Cheng, Y. Phytochemistry 1996, 42, 1657. https://doi.org/10.1016/0031-9422(96)00198-7

5. Kawazoe, K.; Yamamoto, M. ; Takaishi, Y.; Honda, G. ; Fujita, T.; Sezik, E. ; Yesilada, E. Phytochemistry 1999, 50, 493.

https://doi.org/10.1016/S0031-9422(98)00471-3

6. Lin, W. ; Fang, J.; Cheng, Y. Phytochemistry 1995, 40, 871.

https://doi.org/10.1016/0031-9422(95)00358-E

7. 7. Chang, C.; Chien, S.; Lee, S.; Kuo, Y. Chem. Pharm. Bull. 2003, 51, 1420. https://doi.org/10.1248/cpb.51.1420

8. For an excellent review on fluorenone and fluorene containing natural products, see; Shi, Y.; Gao, S. Tetrahedron 2016, 72, 1717.

https://doi.org/10.1016/j.tet.2016.02.022

9. Chang, C. -I.; Chang, J. -Y.; Kuo, C. -C.; Pan, W. -Y.; Kuo, Y. -H. Planta Med. 2005, 71, 72. https://doi.org/10.1055/s-2005-837754

10. Iwamoto, M.; Ohtsu, H.; Tokuda, H.; Nishino, H.; Matsunaga, S.; Tanaka, R. Bioorg. Med. Chem. 2001, 9, 1911.

https://doi.org/10.1016/S0968-0896(01)00099-2

11. Minami, T.; Iwamoto, M.; Ohtsu, H.; Ohishi, H.; Tanaka, R.; Yoshitake, A. Planta Med. 2002, $68,742$. https://doi.org/10.1055/s-2002-33787

12. Hanson, J. Nat. Prod. Rep. 2004, 21, 312.

13. For syntheses of [6-5-6] and [6-5-5]tricyclic core embedded heterocycles, see; Singh, R.; Parai, M. K.; Panda, G. Org. Biomol. Chem. 2009, 7, 1858.

https://doi.org/10.1039/b901632e

14. For syntheses of tricyclic core embedded polycycles, see; Singh, R.; Panda, G. Org. Biomol. Chem. 2011, 9, 4782.

https://doi.org/10.1039/c0ob00892c

15. For syntheses of [6-5-6]-carbotricyclic core via organocatalysis, see; Wu, X.; Li, M.-L.; Chen, D.-F.; Chen, S.-S. J. Org. Chem. 2014, 79, 4743.

https://doi.org/10.1021/jo5006729

16. Guardia, J. J.; Tapia, R.; Mahdjour, S.; Rodriguez-Serrano, F.; Mut-Salud, N.; Chahboun, R.; AlvarezManzaneda, E. J. Nat. Prod. 2017, 80, 308.

https://doi.org/10.1021/acs.jnatprod.6b00700

17. Katoh, T.; Akagi, T.; Noguchi, C.; Kajimoto, T.; Node, M.; Tanaka, R.; Nishizawa, M.; Ohtsu, H.; Suzuki, N.; Saito, K. Bioorg. Med. Chem. 2007, 15, 2736.

https://doi.org/10.1016/i.bmc.2007.01.031

18. For a summary of biogenetic proposal, see; Katakawa, K. J. Syn. Org. Chem. (Japan) 2014, $72,305$. https://doi.org/10.5059/yukigoseikyokaishi.72.305

19. Jana, C. K.; Scopelliti, R.; Gademann, K. Chem. -Eur. J. 2010, 16, 7692.

https://doi.org/10.1002/chem.201001085

20. Thommen, C.; Jana, C. K.; Neuburger, M.; Gademann, K. Org. Lett. 2013, 15, 1390. https://doi.org/10.1021/ol4003652

21. Alvarez-Manzaneda E.; Chahboun R.; Alvarez, E.; Tapia, R.; Alvarez-Manzaneda R. Chem. Commun., 2010, 46, 9244.

https://doi.org/10.1039/c0cc03763j

22. Lin, W. H.; Fang, J. M.; Cheng, Y. S. Phytochemistry 1995, 40, 871.

https://doi.org/10.1016/0031-9422(95)00358-E 
23. Lin, W. H.; Fang, J. M.; Cheng, Y. S. Phytochemistry 1996, 42, 1657.

https://doi.org/10.1016/0031-9422(96)00198-7

24. Cheng recognized the rearranged abietane core, but only referred to it as "the uncommon skeleton of fused 6-5-6 rings" probably arising from abietane diterpenoids.

25. For a review on this historically important class having a fused $[6,5,6]$-system, see: Mander, L. N. Nat. Prod. Rep. 2003, 20, 49 and references therein.

https://doi.org/10.1039/b007744p

26. Kawazoe, K.; Yamamoto, M.; Takaishi, Y.; Honda, G.; Fujita, T.; Sesik, E.; Yesilada, E. Phytochemistry 1999, 50, 493.

https://doi.org/10.1016/S0031-9422(98)00471-3

27. Ohtsu, H.; Iwamoto, M.; Ohishi, H.; Matsunaga, S.; Tanaka, R. Tetrahedron Lett. 1999, 40, 6419. https://doi.org/10.1016/S0040-4039(99)01191-0

28. Chang, C. I.; Chien, S. C.; Lee, S. M.; Kuo, Y. H. Chem. Pharm. Bull. 2003, 51, 1420. https://doi.org/10.1248/cpb.51.1420

29. Chang, C. I.; Chang, J. Y.; Kuo, C. C.; Pan, W. Y.; Kuo, Y. H. Planta Med. 2005, 71, 72. https://doi.org/10.1055/s-2005-837754

30. Lin, W. -H.; Fang, J. -M.; Cheng, Y. -S. Phytochemistry. 1997, 46, 169. https://doi.org/10.1016/S0031-9422(97)00267-7

31. 31Banerjee M.; Mukhopadhyay, R.; Achari, B.; Banerjee, A. Org. Lett. 2003, 5, 3931. https://doi.org/10.1021/ol035506b

32. Banerjee M.; Mukhopadhyay, R.; Achari, B.; Banerjee, A. J. Org. Chem. 2006, 71, 2787. https://doi.org/10.1021/jo052589w

33. Fillion E.; Fishlock D. J.Am. Chem. Soc. 2005, 127, 13144. https://doi.org/10.1021/ja054447p

34. Planas, L.; Mogi, M.; Hirofumi, T.; Kajimato, T.; Node, M. O. J. Org. Chem. 2006, 71, 2896. https://doi.org/10.1021/jo052454q

35. G. Liang, Y. Xu, I. B. Seiple, D. Trauner J. Am. Chem. Soc. 2006, 128, 11022. https://doi.org/10.1021/ja062505g

36. Li, S.; Chiu, P. Tetrahedron Lett. 2008, 49, 1741. https://doi.org/10.1016/i.tetlet.2008.01.084

37. Tang, S.; Xu, Y.; He, J.; Zheng, J.; Pan, X.; She, X. Org. Lett. 2008, 10, 1855. https://doi.org/10.1021/ol800513v

38. Majetich, G.; Shimkus, J. M. Tetrahedron Lett. 2009, 50, 3311. https://doi.org/10.1016/j.tetlet.2009.02.074

39. Alvarez-Manzaneda E.; Chahboun R.; Cabrera, E.; Alvarez, E.; Alvarez-Manzeneda, R.; Meness, R.; EsSamti, H.; Ferna'ndez, A. J. Org. Chem., 2009, 74, 3384.

https://doi.org/10.1021/jo900153y

40. Deng, J.; Li, R.; Luo, Y.; Li, J.; Zhou, S.; Li, Y.; Hu, J.; Li, A. Org Lett. 2013, 15, 2022. https://doi.org/10.1021/ol400717h

41. Padwa, A.; Chughtai, M. J.; Boonsombat, J.; Rashatasakhon, P. Tetrahedron 2008, 64, 4758. https://doi.org/10.1016/i.tet.2008.01.129

42. Ishiyama, T.; Miyaura, N.; Suzuki, A. Org. Synth. 1993, 71, 89. https://doi.org/10.15227/orgsyn.071.0089

43. Winne, J. M.; Guang, B.; Dherde, J.; De Clercq, P. J. Org. Lett. 2006, 8, 4815. https://doi.org/10.1021/ol061962z

44. Wilds, A. L.; Meader, Jr. A. L. J. Org. Chem. 1948, 13, 763. https://doi.org/10.1021/jo01163a024 
45. Sudrik, S. G.; Chavan, S. P.; Chandrakumar, K. R. S.; Pal, S.; Date, S. K.; Chavan, S. P.; Sonawane, H. R. J. Org. Chem. 2002, 67, 1574.

https://doi.org/10.1021/jo010951a

46. Ito, Y.; Hirao, T.; Saegusa, T. J. Org. Chem. 1978, 43, 1011.

https://doi.org/10.1021/jo00399a052

47. Yan, X.; Hu, X. J. Org. Chem. 2014, 79, 5282.

https://doi.org/10.1021/jo5008652

48. Tomooka, C. S.; Liu, H.; Moore, H. W. J. Org. Chem. 1996, 61, 6009.

https://doi.org/10.1021/j0960421s

49. Huang, X.; Song, L.; Xu, J.; Zhu, G.; Liu, B. Angew. Chem., Int. Ed. 2013, 52, 952.

https://doi.org/10.1002/anie.201208687

50. Kakde, B. N.; Kumari, P.; Bisai, A. J. Org. Chem. 2015, 80, 9889.

https://doi.org/10.1021/acs.joc.5b01345

51. Kakde, B. N.; De, S.; Dey, D.; Bisai, A. RSC Adv. 2013, 3, 8176.

https://doi.org/10.1039/c3ra41497c

52. Kakde, B. N.; Parida, A.; Kumari, P.; Bisai, A. Tetrahedron Lett. 2016, 57, 3179.

https://doi.org/10.1016/i.tetlet.2016.06.030

53. Kakde, B. N.; Parida, A.; Kumar, N.; Mourya, A.; Bisai, A. ChemistrySelect 2016, 1, 3357.

https://doi.org/10.1002/slct.201600890

54. McFadden, R. M.; Stoltz, B. M. J. Am. Chem. Soc. 2006, 128, 7738.

https://doi.org/10.1021/ja061853f

55. Smith, A. B., III; Cho, Y. S.; Friestad, G. K. Tetrahedron Lett. 1998, 39, 8765.

https://doi.org/10.1016/S0040-4039(98)01992-3

56. Thomas, A. F.; Ozainne, M.; Guntz-Dubini, R. Can. J. Chem. 1980, 58, 1810.

https://doi.org/10.1139/v80-286

57. Alvarez-Manzaneda E.; Chahboun R.; Cabrera, E.; Alvarez, E.; Haidour, A.; Ramos, J. M.; AlvarezManzeneda, R.; Hmamouchi, M.; Es-Samti, H. Chem. Commun. 2009, 592.

https://doi.org/10.1039/B816812A

58. Alvarez-Manzaneda E.; Chahboun R.; Cabrera, E.; Alvarez, E.; Haidour, A.; Ramos, J. M.; AlvarezManzeneda, R.; Charrah, Y.; Es-Samti, H. Org. Biomol. Chem. 2009, 7, 5146.

https://doi.org/10.1039/b916209g

59. Node, M.; Ozeki, M.; Planas, I.; Nakano, M.; Takita, H.; Mori, D.; Tamatani, S.; Kajimato, T. O. J. Org. Chem. 2010, 75, 190.

https://doi.org/10.1021/jo901972b

60. Ozeki, M.; Satake, M.; Toizume, T.; Fukutome, S.; Arimitsu, K.; Hosai, S.; Kajimato, T.; Iwasaki, N.; Kajima, N.; Node, M.; Yamashita, M. O. Tetrahedron, 2013, 69, 3841.

https://doi.org/10.1016/i.tet.2013.03.051

61. Tapia, R.; Guardia, J. J.; Alvarez, E.; Haidour, A.; Ramos, J. M.; Alvarez-Manzaneda R.; Chahboun R.; Alvarez-Manzaneda, E. J. Org. Chem. 2012, 77, 573.

https://doi.org/10.1021/jo202163y

62. Lin, W. H. ; Fang, J. M. ; Cheng, Y. S. Phytochemistry 1995, 40, 871.

https://doi.org/10.1021/jo202163y

63. Geiwiz, J.; Haslinger, E. Helv. Chim. Acta 1995, 78, 818.

https://doi.org/10.1002/hlca.19950780404

64. Sharpless, K. B.; Amberg, W.; Bennani, Y. L.; Crispino, G. A.; Hartung, J.; Jeong, K.-S.; Kwong, H.-L.; Morikawa, K.; Wang, Z.-M.; Xu, D.; Zhang, X.-L. J. Org. Chem. 1992, 57, 2768.

https://doi.org/10.1021/jo00036a003

65. Meyer, N.; Seebach, D. Angew. Chem. Int. Ed. 1978, 17, 521. 
https://doi.org/10.1002/anie.197805211

66. Loh, T. P.; Hu, Q. Y. Org. Lett. 2001, 3, 279.

https://doi.org/10.1021/ol006918c

67. Liao, X.; Stanley, L. M.; Hartwig, J. F. J. Am. Chem. Soc. 2011, 133, 2088.

https://doi.org/10.1021/ja110215b

68. Chieffi, A.; Kamikawa, K.; Ahman, J.; Fox, J. M.; Buchwald, S. L. Org. Lett. 2001, 3, 1897.

https://doi.org/10.1021/ol0159470

69. Woodward, R. B.; Sondheimer, F.; Taub, D.; Heusler, K.; McLamore, W. M. J. Am. Chem. Soc. 1952, 74, 4223.

https://doi.org/10.1021/ja01137a001

70. Corey, E. J.; Chaykovsky, M. J. Am. Chem. Soc. 1962, 84, 867.

https://doi.org/10.1021/ja00864a040

71. Corey, E. J.; Chaykovsky, M. J. Am. Chem. Soc. 1962, 84, 3782.

https://doi.org/10.1021/ja00878a046

72. Corey, E. J.; Chaykovsky, M. J. Am. Chem. Soc. 1965, 87, 1353.

https://doi.org/10.1021/ja01084a034

73. Shockley, S. E.; Holder, J. C.; Stoltz, B. M. Org. Lett. 2014, 16, 6362.

https://doi.org/10.1021/ol5031537

74. Kikushima, K.; Holder, J. C.; Gatti, M.; Stoltz, B. M. J. Am. Chem. Soc. 2011, 133, 6902.

https://doi.org/10.1021/ja200664x

\section{Authors' Biographies}

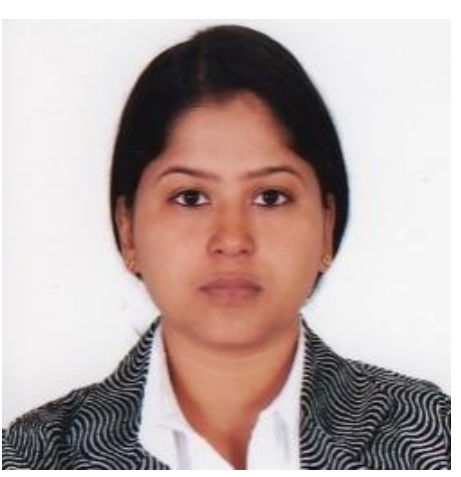

Vishnumaya Bisai was born in Gorakhpur, India on August 30, 1979. She completed M.Sc. in Chemistry from DDU Gorakhpur University, India in July 2002 and Ph.D. in the area of organocatalytic Carbon-Carbon bondforming reactions with Prof. Vinod K. Singh from the Indian Institute of Technology (IIT) Kanpur, India in January, 2009. Immediately afterward, she started post-doctoral research in the area of total synthesis of lycopodium alkaloids with Prof. Richmond Sarpong from the University of California (UC), Berkeley, USA and continued till November, 2010. She joined the Department of Applied Sciences, National Institute of Technical Teachers' Training and Research (NITTTR), Bhopal, India as an Assistant Professor of Chemistry (Apr., 2011 Apr. 2012). After spending 3 years at IISER Bhopal (Sr. Research Scientist during May, 2012 - July, 2014 and Visiting Faculty during Aug. 2014 - Aug. 2015), she joinded as an Assistant Professor in the Department of Chemistry, IISER Tirupati (Aug. 2015 - July. 2016). Later, she moved to the Department of Chemistry, IISER Berhampur as an Assistant Professor of Chemistry in Aug. 2016. Her research interest involves the design and development of enantioenriched ligands and their applications in the area of asymmetric catalysis and stereoselective synthesis of natural/hybrid molecules. 


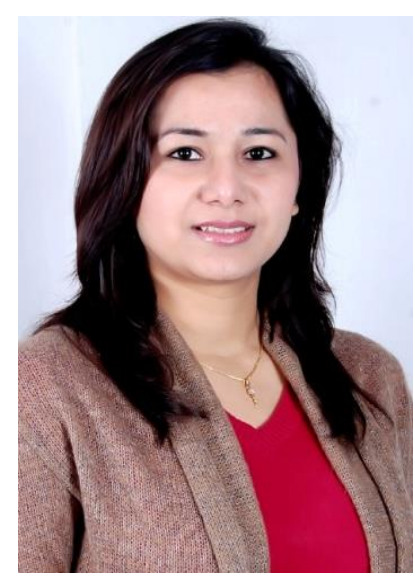

Aditi Gupta completed her Bachelors in Chemistry (Hons.) from St. Stephen's College, Delhi University in 2007 and Masters in Chemistry from IIT Delhi in 2009. She has received prestigious CSIR-JRF and CSIR-SRF fellowships from the Govt. of India and completed her Ph.D. in Applied Chemistry with Prof. Satyawati Sharma from Indian Institute of Technology Delhi, India in 2013. Thereafter, she has been working as an Assistant Professor in the Department of Chemistry, St. Stephen's College, Delhi University. She has over 18 international publications ( $h$-index $=7$ ) in peer reviewed journals and conferences to her credit. Her major research interests include plant metabolites, waste management, biomass to bioenergy conversion, development of biopesticides, nutraceuticals, etc.

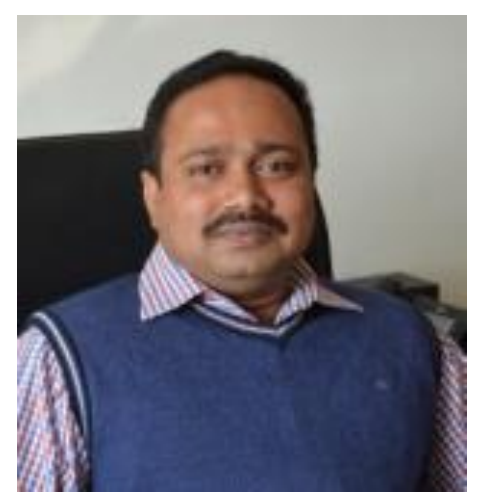

Alakesh Bisai received his M.Sc. degree in Organic Chemistry from Banaras Hindu University and obtained Ph.D. in synthetic Organic Chemistry under the supervision of Professor Vinod K. Singh from the Department of Chemistry, Indian Institute of Technology Kanpur in Sept. 2006. Immediately afterward, he moved to the College of Chemistry, University of California at Berkeley, where he held postdoctoral position in the research group of Professor Richmond Sarpong. During his stay at Berkeley, he completed concise total synthesis of 'lycopodium alkaloids' lyconadin A, which received considerable attention from the synthetic community. During his Postdoctoral research, he received the GRC (Gordon Research Conference) award to Post-docs by Chair, $17^{\text {th }}$ GRC on Stereochemistry (2008), RI. In Dec. 2009, he left Berkeley and joined the Department of Chemistry, IISER Bhopal as an Assistant Professor. In Nov. 2013, he was appointed as an Associate Professor in the Department Chemistry. The research focus of the $A B$ research group includes the total synthesis of architecturally interesting biologically active natural products that provide an ideal platform for the invention of new strategies and highly selective organic transformations. A number of naturally occurring architecturally intriguing biological relevant secondary metabolites sharing all-carbon quaternary stereocenters have been synthesized by his research group at IISER Bhopal. He is the recipient of Young Scientist Research Grant by the DST (in form of FAST-TRACK grant) (2011) and by the BRNS, DAE (2011). Recently, his total synthesis of pyrroloindoline alkaloids had been highlighted in 'Organic Chemistry Portal' as 'The Bisai Synthesis of (-)- 
Physovenine' (http://www.organic-chemistry.org/Highlights/2016/18July.shtm). Since January, 2018, he has been working as a Professor of Chemistry at IISER Bhopal. 